\title{
Parkin Deficiency Reduces Hippocampal Glutamatergic Neurotransmission by Impairing AMPA Receptor Endocytosis
}

\author{
Giuseppe P. Cortese, ${ }^{1 *} \oplus$ Mei Zhu, ${ }^{1 *}$ Damian Williams, ${ }^{2}$ Sarah Heath, ${ }^{3}$ and ${ }^{\oplus}$ Clarissa L. Waites ${ }^{1}$ \\ ${ }^{1}$ Department of Pathology and Cell Biology, ${ }^{2}$ Columbia Stem Cell Core Facility, Department of Pathology and Cell Biology, and ${ }^{3}$ Graduate Program in \\ Neurobiology and Behavior, Columbia University Medical Center, New York, New York 10032
}

\begin{abstract}
Mutations in the gene encoding Parkin, an E3 ubiquitin ligase, lead to juvenile-onset Parkinson's disease by inducing the selective death of midbrain dopaminergic neurons. Accumulating evidence indicates that Parkin also has an important role in excitatory glutamatergic neurotransmission, although its precise mechanism of action remains unclear. Here, we investigate Parkin's role at glutamatergic synapses of rat hippocampal neurons. We find that Parkin-deficient neurons exhibit significantly reduced AMPA receptor (AMPAR)mediated currents and cell-surface expression, and that these phenotypes result from decreased postsynaptic expression of the adaptor protein Homer1, which is necessary for coupling AMPAR endocytic zones with the postsynaptic density. Accordingly, Parkin loss of function leads to the reduced density of postsynaptic endocytic zones and to impaired AMPAR internalization. These findings demonstrate a novel and essential role for Parkin in glutamatergic neurotransmission, as a stabilizer of postsynaptic Homer1 and the Homer1linked endocytic machinery necessary for maintaining normal cell-surface AMPAR levels.
\end{abstract}

Key words: AMPA receptor; endocytic zone; Homer; Parkin; synapse

\section{Significance Statement}

Mutations in Parkin, a ubiquitinating enzyme, lead to the selective loss of midbrain dopaminergic neurons and juvenile-onset Parkinson's disease (PD). Parkin loss of function has also been shown to alter hippocampal glutamatergic neurotransmission, providing a potential explanation for PD-associated cognitive impairment. However, very little is known about Parkin's specific sites or mechanisms of action at glutamatergic synapses. Here, we show that Parkin deficiency leads to decreased AMPA receptormediated activity due to disruption of the postsynaptic endocytic zones required for maintaining proper cell-surface AMPA receptor levels. These findings demonstrate a novel role for Parkin in synaptic AMPA receptor internalization and suggest a Parkin-dependent mechanism for hippocampal dysfunction that may explain cognitive deficits associated with some forms of PD.

\section{Introduction}

Loss-of-function mutations in the PARK2 gene, encoding the E3 ubiquitin ligase Parkin, are the leading cause of juvenile-onset,

Received May 5, 2016; revised Sept. 19, 2016; accepted Oct. 18, 2016.

Author contributions: G.P.C., M.Z., D.W., and C.L.W. designed research; G.P.C., M.Z., S.H., and C.L.W. performed research; D.W. contributed unpublished reagents/analytic tools; G.P.C., M.Z., S.H., and C.L.W. analyzed data; G.P.C., M.Z., and C.L.W. wrote the paper.

This work was supported by Columbia University startup funds (Departments of Pathology and Cell Biology and Neuroscience), National Institutes of Health Grant NS080967 (to C.L.W.), and a Brain Research Foundation seed grant to C.L.W. We thank Dr. Amy MacDermott for helpful discussions and Cyndel Vollmer for preparation of glial microislands. We also thank C. Corona, D. Pre, M. Fa, and J. Smerdon for scientific input and P. Sheehan and A. Beskow for preparation of hippocampal cultures from Parkin KO rats.

*G.P.C. and M.Z. contributed equally to this work.

The authors declare no competing financial interests.

Correspondence should be addressed to Dr. Clarissa L. Waites, Departments of Pathology and Cell Biology and Neuroscience, 650 W. 168th Street, New York, NY 10032. E-mail: cw2622@cumc.columbia.edu. autosomal recessive Parkinson's disease (PD; Leroy et al., 1998; Lucking et al., 1998). PD results from the selective loss of midbrain dopaminergic neurons, whose survival depends on Parkinmediated mitophagy downstream of the kinase PINK1 (Feany and Pallanck, 2003; Greene et al., 2003; Berger et al., 2009; Wang et al., 2011). However, Parkin is highly expressed throughout the nervous system (Scuderi et al., 2014), and some PD symptoms, such as cognitive decline and dementia, are suggestive of hippocampal dysfunction (Svenningsson et al., 2012; Calabresi et al., 2013; Cosgrove et al., 2015). Moreover, Parkin deficiency has recently been associated with Alzheimer's disease and autism (Scheuerle and Wilson, 2011; Roberts et al., 2014; Sun et al., 2014; Olah et al., 2015), disorders linked to dysfunctional glutamatergic 
neurotransmission in the hippocampus (Penzes et al., 2013; Bartsch and Wulff, 2015; Raskin et al., 2015). In addition, Parkininteracting partners and substrates include many components of glutamatergic synapses, including the endocytic protein endophilin-A, the PDZ domain-containing proteins CASK and PICK1, and the kainate receptor subunit GluK2 (Fallon et al., 2002; Joch et al., 2007; Trempe et al., 2009; Maraschi et al., 2014), and multiple groups have reported that Parkin loss of function alters glutamatergic synaptic transmission and plasticity (Goldberg et al., 2003; Itier et al., 2003; Helton et al., 2008; Kitada et al., 2009; Hanson et al., 2010; Rial et al., 2014). However, the conclusions from these studies are oftentimes contradictory, and none has clearly separated the effects of presynaptic versus postsynaptic Parkin loss on neurotransmission. Such an analysis is necessary to fully understand Parkin's roles at glutamatergic synapses, since its substrates/interacting partners include presynaptic and postsynaptic proteins, and its loss of function likely has distinct effects in each compartment.

Here, we have used single- and paired-cell electrophysiological recordings, biochemistry, and immunofluorescence microscopy to examine Parkin's role at glutamatergic hippocampal synapses. We find that Parkin deficiency leads to a significant reduction in AMPAtype glutamate receptor (AMPAR)-mediated currents and cellsurface expression, and that these phenotypes are linked to decreased postsynaptic expression of Homer1, a scaffold protein necessary for coupling endocytic zones (EZs) for AMPAR internalization to the postsynaptic density (PSD; Lu et al., 2007). Correspondingly, we show that EZ density is decreased and AMPAR internalization is impaired in Parkin-deficient neurons. Our findings demonstrate that Parkin has a critical role in stabilizing postsynaptic Homer1 and the Homer1-linked EZs required for AMPAR capture and retention at synapses, and that Parkin loss of function leads to decreased cellsurface AMPAR levels and signaling.

\section{Materials and Methods}

Reagents. The following primary antibodies and dilutions were used for immunoblotting and immunoprecipitation: mouse Parkin (Prk8, 1:1000; Santa Cruz Biotechnology), rabbit GAPDH (1:500; Santa Cruz Biotechnology), rabbit GluA1 (1:1000; Cell Signaling), rabbit GluA2/3 (1:1000; EMD Millipore), rabbit CaMKII (1:700; Cell Signaling), rabbit CASK (1:500; Cell Signaling), rabbit PSD-95 (1:1000; Cell Signaling), rabbit Homer1b/c (1:1000; Santa Cruz Biotechnology), mouse tubulin (1:10,000; Sigma), rabbit tubulin (1:10,000; Abcam), rabbit GFP (1:1000; Invitrogen), mouse Myc (1:500; Santa Cruz Biotechnology), rabbit HA (1:500; Santa Cruz Biotechnology). HRP-conjugated secondary antibodies were purchased from Bio-Rad and diluted 1:5000-10,000, and DyLight fluorescent secondary antibodies were purchased from Thermo Fisher Scientific and diluted 1:10,000-15,000. The following primary antibodies and dilutions were used for immunostaining: mouse VAMP2 (1:1000; Synaptic Systems), rabbit Homer 1, isoforms a-c (1:200; Synaptic Systems), mouse GluA1 (1:50; EMD Millipore), mouse GluA2 (1:100; EMD Millipore), mouse HA (F7, 1:200; Santa Cruz Biotechnology), unconjugated anti-mouse secondary antibody (1:50; Invitrogen). Parkin knock-out (KO) rats were purchased from SAGE Labs/Horizon Discovery, and PINK KO rats (SAGE Labs/Horizon Discovery) were a generous gift from Dr. M. Ciucci (University of Wisconsin, Madison, Wisconsin, USA). Unless otherwise indicated, all other chemicals are from Sigma-Aldrich.

Primary hippocampal culture. Rat primary hippocampal cultures were prepared using a modified Banker culture protocol (Banker and Goslin, 1998; Waites et al., 2009). Briefly, neurons from embryonic (E18-E19) Sprague Dawley rat hippocampi, taken from animals of both sexes, were dissociated in TrypLE Express (Invitrogen) for $20 \mathrm{~min}$, washed with HBSS (Sigma), and plated in Neurobasal medium with B27 supplement and Glutamax (all from Invitrogen) at a density of 250,000 neurons per well (12-well plates) or coverslip $(22 \times 22 \mathrm{~mm}$ square $)$ or $75,000-$ 100,000 neurons per coverslip for glial microisland cultures.

Primary astrocyte culture and microislands. Primary astrocytes and astrocyte microislands were prepared as described previously (DelgadoMartinez et al., 2007; Albuquerque et al., 2009). Cortices from P0 -P2 rat pups were removed, chopped into $1 \mathrm{~mm}^{3}$ chunks, digested with TrypLE Express for $30 \mathrm{~min}$ at $37^{\circ} \mathrm{C}$, and triturated to dissociate the cells. The cell mixture was spun at $1000 \mathrm{rpm}$ for $8 \mathrm{~min}$, resuspended in astrocyte medium, and plated into T75 flasks. Two to three days after culturing, astrocytes were washed in ice-cold PBS, followed by ice-cold astrocyte medium. Seven to 10 days after culturing, $\operatorname{AraC}(1 \mu \mathrm{M})$ was added to each flask and allowed to incubate overnight. The following day, cultures were shaken for 4-6 h at room temperature and washed with ice-cold PBS $\left(\mathrm{Ca}^{2+} / \mathrm{Mg}^{2+}\right.$ free $)$. Cells were then trypsinized for $15 \mathrm{~min}$ and replated into T75 flasks. They were then grown to confluence (with medium changed once per week) and used for microislands after this time. For microisland preparation, $22 \mathrm{~mm}$ coverslips were etched in $70 \%$ nitric acid overnight, washed three times in double-deionized $\mathrm{H}_{2} \mathrm{O}\left(\mathrm{dd}_{2} \mathrm{O}\right)$, sterilized in $100 \%$ ethanol, and coated with poly-L-lysine $(0.25 \mathrm{mg} / \mathrm{ml})$ for $2 \mathrm{~h}$. After three washes in $\mathrm{ddH}_{2} \mathrm{O}$, coverslips were coated with agarose $(0.25 \%)$ and allowed to dry overnight. Agarose-coated coverslips were stamped with a grid stamper containing rat-tail collagen (Invitrogen) and astrocytes plated at 50,000 cells per coverslip. Two days later, neurons were plated onto microislands at a density of 75-100,000 neurons per coverslip.

Expression constructs and transduction/transfection. Parkin shRNAs were designed corresponding to the 21-mer target sequences (with twonucleotide $5^{\prime}$ overhang) generated by siDirect (sidirect2.rnai.jp). The target sequence of shParkin is gcaatgtgcccattgaaaa (corresponding to nucleotides 1262-1281 of Rattus norvegicus Parkin, GenBank accession number AB039878.1). Oligonucleotides containing the shParkin target sequence flanked by BglII and HindIII sites and hairpin loops were subcloned into pZOff 2.0 vector and subsequently into pFUGW H1 and pF-SAP102-GFP-W H1 (a gift from C. Garner, Stanford University, Stanford, CA; now at Universitätsmedizin Berlin, Berlin, Germany) as described previously (Leal-Ortiz et al., 2008) to create pFUGW $\mathrm{H} 1+$ shParkin and pFU-SAP102-GFP-W+shParkin. Human Parkin (Parkin) was purchased from Addgene (plasmid 45876) and subcloned into the pFUGW and pFUGW H1+ shParkin vectors at the XbaI/EcoRI sites. The GFP-Homer1 construct was a gift from A. M. Grabrucker (University of Ulm, Ulm, Germany) and C. Garner. pFUGW constructs were used to generate lentivirus for infection of primary neurons as described previously (Leal-Ortiz et al., 2008), except that Calfectin (SignaGen Laboratories) was used for transfection of HEK293T cells. HEK medium was replaced with Neurobasal medium 18-24 h after transfection, and this medium (viral supernatant) was harvested $24 \mathrm{~h}$ later. Neurons were transduced with $50-200 \mu \mathrm{l}$ of lentiviral supernatant per well at $2-3 \mathrm{~d}$ in vitro (DIV) and used for experiments between 13-15 DIV. This time course was optimized based on efficacy of the shRNA knockdown. Transfections were performed on 5 DIV using Lipofectamine 2000 (Invitrogen). For each $22 \times 22 \mathrm{~mm}$ coverslip, $2.5 \mu \mathrm{l}$ of Lipofectamine was incubated with $62.5 \mu \mathrm{l}$ of Neurobasal medium for $5 \mathrm{~min}$, combined with $1-2.5 \mu \mathrm{g}$ of DNA diluted in $62.5 \mu \mathrm{l}$ of Neurobasal medium for $20 \mathrm{~min}$, and added to neurons for $45 \mathrm{~min}$ at $37^{\circ} \mathrm{C}$. Neurons were transfected in Neurobasal medium containing $50 \mu \mathrm{M}$ AP-5 and $10 \mu \mathrm{M}$ CNQX and returned to their original dishes and medium after transfection.

Electrophysiology. Whole-cell patch-clamp recordings were performed to examine miniature EPSCs (mEPSCs) and evoked EPSCs (eEPSCs) as described previously (Waites et al., 2009; Arons et al., 2012). mEPSCs and eEPSCs were measured at 13-15 DIV from hippocampal pyramidal neurons plated onto glial islands and transduced with the following constructs: pFU-GFP-W (soluble GFP control), pFU-GFP-humanParkin-W (Parkin), pFUGW H1 plus shParkin (shParkin), or pFU-GFPhuman-Parkin-W plus shParkin (rescue). Cultures were perfused at room temperature with an extracellular solution $(145 \mathrm{~mm} \mathrm{NaCl}, 5 \mathrm{~mm}$ $\mathrm{KCl}, 10 \mathrm{~mm}$ HEPES, $1.3 \mathrm{~mm} \mathrm{MgCl}_{2}, 2 \mathrm{~mm} \mathrm{CaCl}_{2}, 10 \mathrm{~mm}$ glucose) containing $1 \mu \mathrm{m}$ of TTX (mEPSCs only) and $100 \mu \mathrm{m}$ of picrotoxin. Neurons were visualized by fluorescence microscopy, and those expressing GFP were selected as postsynaptic, whereas uninfected (nonfluorescent) neu- 
rons were selected as presynaptic. Our cocultures contained a high concentration of mixed GFP +/ - synapses and very few GFP +/+ synapses. For spontaneous events, neurons were held at $-65 \mathrm{mV}$ and mEPSCs were recorded over 5 min using a MultiClamp 700B amplifier (Molecular Devices) controlled with a PC running MultiClamp Commander and pClamp (Molecular Devices) and pass filtered at $2 \mathrm{kHz}$. For evoked currents (eEPSCs), postsynaptic neurons were voltage clamped at $-65 \mathrm{mV}$ whereas presynaptic neurons were held in current clamp and induced to fire action potentials by brief injection of depolarizing current. The threshold for action potential firing was determined for each presynaptic neuron, and the current was set accordingly. The internal solution consisted of the following: for postsynaptic cell: $110 \mathrm{~mm}$ Cs-methanesulfonate, $10 \mathrm{~mm} \mathrm{Na}$ methanesulfonate, 10 mм EGTA, 1 mm CaCl , 10 mм HEPES, 10 mm TEA, 5 mM QX-314, 5 mм MgATP, 0.5 mM NaGTP; for presynaptic cell: $130 \mathrm{~mm}$ K-methanesulfonate, $10 \mathrm{~mm}$ Na-methanesulfonate, $10 \mathrm{~mm}$ EGTA, $1 \mathrm{~mm}$ $\mathrm{CaCl}_{2}$, 10 mм HEPES, 5 mм MgATP, 0.5 mм NaGTP. Monosynaptic excitatory connections were evident as an inward current into the postsynaptic neuron occurring within $5 \mathrm{~ms}$ of the peak of the presynaptic action potential. Failures of synaptic transmission were defined as trials indistinguishable from baseline and were evident by a lack of postsynaptic current immediately after the presynaptic action potential. For evoked EPSCs, action potentials were evoked at $0.2 \mathrm{~Hz}$. A series of 10 independent stimulations were conducted for each paired whole-cell recording, and the amplitudes were averaged over this series. AMPAR-mediated currents were measured after local application of the AMPAR agonist kainite (100 $\mu$ m; Tocris Bioscience) using a custom-built application system $\sim 200 \mu \mathrm{m}$ from synapsing neurons on a specific microisland.

Data analysis. Data acquisition and off-line analysis of AMPARmediated EPSCs were performed with pClamp (Clampex version 10.4). Statistical analyses were performed in GraphPad Prism using one-way ANOVA or unpaired, two-tailed $t$ tests, with $p<0.05$ considered significant. mEPSCs were detected and analyzed with MiniAnalysis (version 6.0.3; Synaptosoft) as described previously (Waites et al., 2009).

Preparation of postsynaptic densities. Anesthetized rats [Long-Evans hooded wild type (WT), Parkin KO, and PINK1 KO] were decapitated, hippocampi were extracted, and PSD fractions were prepared as described previously (Bermejo et al., 2014). Tissue was minced in $4 \mathrm{ml}$ of homogenization buffer $(\mathrm{HB})$ with protease inhibitors ( $0.32 \mathrm{M}$ sucrose in 4 mM HEPES) and homogenized using a glass tissue grinder with a Teflon pestle. Nuclear material and unbroken cells were removed by centrifugation at $900 \times g$ for $10 \mathrm{~min}$. The remaining supernatant was centrifuged at $10,000 \times g$ for 15 min, yielding an S2 cytosolic fraction and a P2 crude synaptoneurosomal fraction containing both presynaptic and postsynaptic material. The $\mathrm{P} 2$ synaptoneurosomal pellet was gently washed in 3 $\mathrm{ml}$ of $\mathrm{HB}$ and spun at $10,000 \times g$ for $15 \mathrm{~min}$. The P2 pellet was then homogenized in $3 \mathrm{ml}$ of $\mathrm{ddH}_{2} \mathrm{O}$ using a glass tissue homogenizer with a Teflon pestle. The homogenate was immediately brought back to $4 \mathrm{~mm}$ HEPES concentration and rotated for $30 \mathrm{~min}$ at $4^{\circ} \mathrm{C}$ to ensure complete lysis. The synaptic homogenate was centrifuged at $25,000 \times g$ for $20 \mathrm{~min}$ at $4^{\circ} \mathrm{C}$. The synaptoneurosomal pellet (P3) was resuspended in $1 \mathrm{ml}$ of $\mathrm{HB}$. The P3 sample was layered onto a discontinuous sucrose gradient $(1.2,1.0$, and $0.8 \mathrm{~m}$ sucrose in $4 \mathrm{~mm}$ HEPES). The samples underwent ultracentrifugation in a fixed-angle rotor at $200,000 \times \mathrm{g}$ for $30 \mathrm{~min}$ at $4^{\circ} \mathrm{C}$. The resulting pellet containing synaptic plasma membranes (SPMs) was resuspended in $500 \mu \mathrm{l}$ of $50 \mathrm{~mm}$ HEPES/2 mM EDTA solution (HE). The SPM sample was added to $2.5 \mathrm{ml}$ of lysis buffer $(0.54 \%$ Triton X-100 in HE) and centrifuged at $32,000 \times g$ for $20 \mathrm{~min}$ at $4^{\circ} \mathrm{C}$. The resulting pellet (PSD) was lysed in HE plus $0.01 \%$ SDS. Synaptic enrichment of the PSD fraction was confirmed using common synaptic markers (i.e., PSD95, CaMKII). Protein content was quantified using the BCA protein assay (Bio-Rad). Samples were prepared in reducing $4 \times$ Laemmli buffer and heated at $65^{\circ} \mathrm{C}$ for $5 \mathrm{~min}$ before loading on SDS-PAGE. For Western blotting, $40 \mu \mathrm{g}$ of sample was loaded onto $4-15 \%$ TGX (Bio-Rad) precast gels and transferred onto polyvinylidene fluoride membranes (Millipore). Membranes were blocked in 5\% milk/PBS with $0.01 \%$ Triton $\mathrm{X}-100$ (PBST) for $30 \mathrm{~min}$ at room temperature; all primary antibody incubations were done at $4^{\circ} \mathrm{C}$ overnight, followed by three 10 min washes with PBST; and secondary antibody incubations were done at room temperature for $1 \mathrm{~h}$ and washed three times for $10 \mathrm{~min}$ with PBST. Mem- branes were then scanned and protein levels were detected using the Odyssey CLx imaging system.

Coimmunoprecipitation assay. For coimmunoprecipitation studies, HEK293T cells were transfected using Calfectin according to the manufacturer's (SignaGen Laboratories) protocol. Cell lysates were collected $48 \mathrm{~h}$ after transfection in lysis buffer (50 mm Tris-base, $150 \mathrm{~mm} \mathrm{NaCl}, 1 \%$ Triton X-100, 0.5\% deoxycholic acid) with protease inhibitor mixture (Roche) and clarified by centrifugation at high speed (20,000 rcf). The resulting supernatant was incubated with Dynabeads (Invitrogen) coupled with anti-Myc or control mouse IgG antibodies at $4^{\circ} \mathrm{C}$ under constant rotation for $1-2 \mathrm{~h}$. Beads were washed two to three times with lysis buffer and once with PBS. Bound proteins were eluted using sample buffer (Bio-Rad) and subject to SDS-PAGE immunoblotting as described below.

Immunoblotting. Cultured neurons were collected directly in $2 \times$ SDS sample buffer (Bio-Rad). Samples were subjected to SDS-PAGE, transferred to nitrocellulose membranes, probed with primary antibodies in $5 \%$ BSA/PBS plus $0.05 \%$ Tween 20 overnight at $4^{\circ} \mathrm{C}$, followed by fluorescent or HRP-conjugated secondary antibodies for $1 \mathrm{~h}$. Membranes were imaged using an Odyssey Infrared Imager (model 9120; LI-COR Biosciences) or incubated with SuperSignal West Pico Chemiluminescent substrate (Pierce) and exposed to autoradiography film. Protein bands were quantified using the Image (NIH) "Gels" function, and all bands were normalized to their loading controls. Statistical analyses were performed in GraphPad Prism using unpaired, two-tailed $t$ tests comparing the mean control or WT condition to the knockdown or KO. The $p$ value $(p<0.05)$ was considered significant.

Immunofluorescence microscopy. Primary antibodies and concentrations are listed above. Alexa Fluor 488-, Alexa Fluor 568-, or Alexa Fluor 647-conjugated secondary antibodies (Thermo Fisher Scientific) were used at 1:800 or 1:400 (for Alexa Fluor 647). Neurons were immunostained as described previously (Leal-Ortiz et al., 2008). Briefly, coverslips were fixed with Lorene's fixative ( 60 mM PIPES, 25 mM HEPES, 10 mм EGTA, 2 mм $\mathrm{MgCl}_{2}, 0.12 \mathrm{~m}$ sucrose, 4\% formaldehyde) for $15 \mathrm{~min}$, primary and secondary antibody incubations were performed in blocking buffer (2\% glycine, $2 \% \mathrm{BSA}, 0.2 \%$ gelatin, and $50 \mathrm{~mm} \mathrm{NH}_{4} \mathrm{Cl}$ in $1 \times$ PBS) for $1-2 \mathrm{~h}$ at room temperature or overnight at $4^{\circ} \mathrm{C}$, and all washes were done with PBS. For surface labeling, GluA1 or GluA2 antibodies were added to live neurons at 1:100 concentration, incubated for $5 \mathrm{~min}$ at $37^{\circ} \mathrm{C}$, washed three times in Neurobasal medium, and fixed and stained with secondary antibodies as described. Coverslips were mounted with DAPI VectaShield (Vector Laboratories) and sealed with clear nail polish. Images were acquired with a $40 \times$ objective (Neofluar, NA 1.3) or a $63 \times$ objective (Neofluar, NA 1.4) on an epifluorescence microscope (Axio Observer Z1; Zeiss) with Colibri LED light source, EMCCD camera (Hamamatsu), and Zen 2012 (blue edition) software or with the same objectives on a Zeiss LSM 800 confocal microscope running Zen2 software.

GluA1 internalization assay. GluA1 internalization was measured using a protocol modified from Lu et al. (2007) and Piguel et al. (2014). Neurons expressing GFP $+/-$ shParkin were incubated with mouse GluA1 antibody (1:50; Millipore) for $40 \mathrm{~min}$ at $25^{\circ} \mathrm{C}$ to label surface AMPARs, washed four times with PBS, and either fixed immediately with Lorene's fixative or incubated at $37^{\circ} \mathrm{C}$ for 15 or $30 \mathrm{~min}$ before fixation to allow for receptor internalization. Cells were then incubated with antimouse Alexa Fluor 568 secondary antibody diluted in blocking buffer (used for all remaining steps) for $40 \mathrm{~min}$ at room temperature, washed three times, and incubated for $30 \mathrm{~min}$ with unconjugated anti-mouse secondary antibody to block any remaining unlabeled cell-surface GluA1 antibody. Finally, cells were washed four times, permeabilized with $0.25 \%$ Triton $\mathrm{X}-100$, and incubated for $1 \mathrm{~h}$ at $25^{\circ} \mathrm{C}$ with anti-mouse Alexa Fluor 647 to label internalized GluA1.

GluA1 recycling assay. Neurons were incubated with anti-GluA1 antibody to label surface receptors as described above and incubated at $37^{\circ} \mathrm{C}$ for $30 \mathrm{~min}$ to allow for receptor internalization. All noninternalized surface antibody was subsequently blocked with an unconjugated antimouse secondary antibody at $25^{\circ} \mathrm{C}$ for $30 \mathrm{~min}$ and washed four times in PBS. Next, neurons were fixed or incubated at $37^{\circ} \mathrm{C}$ for $1 \mathrm{~h}$ to allow for receptor recycling back to the plasma membrane. They were then fixed, 


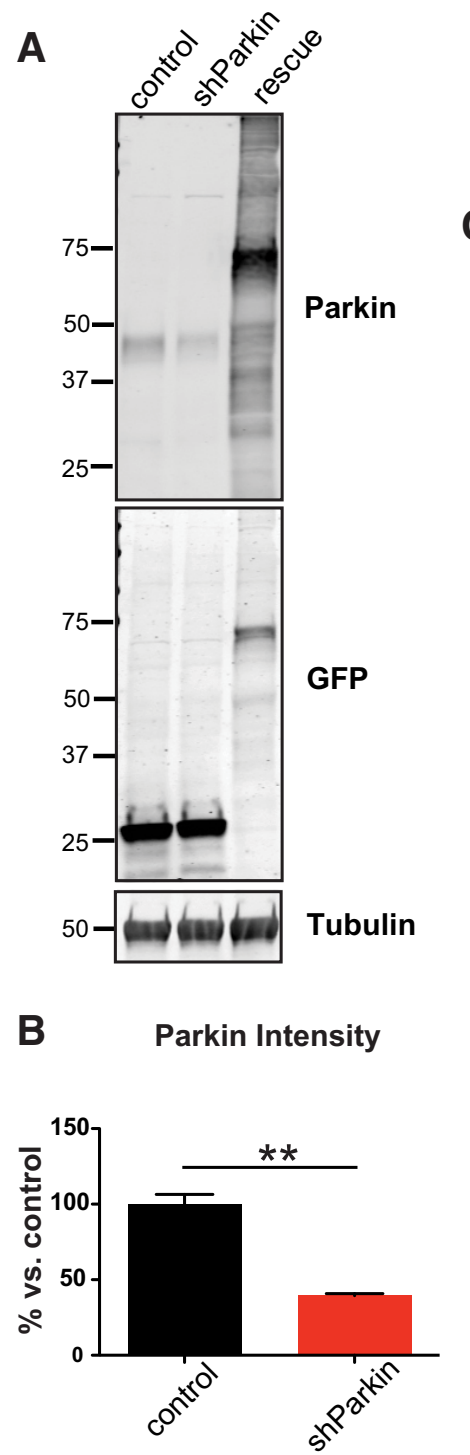

C

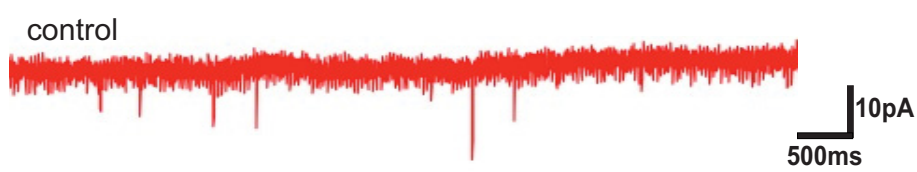

Parkin
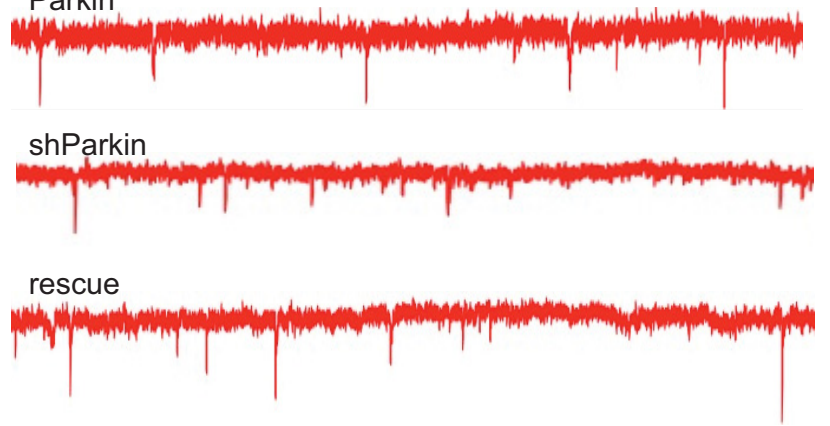

$\mathbf{F}$
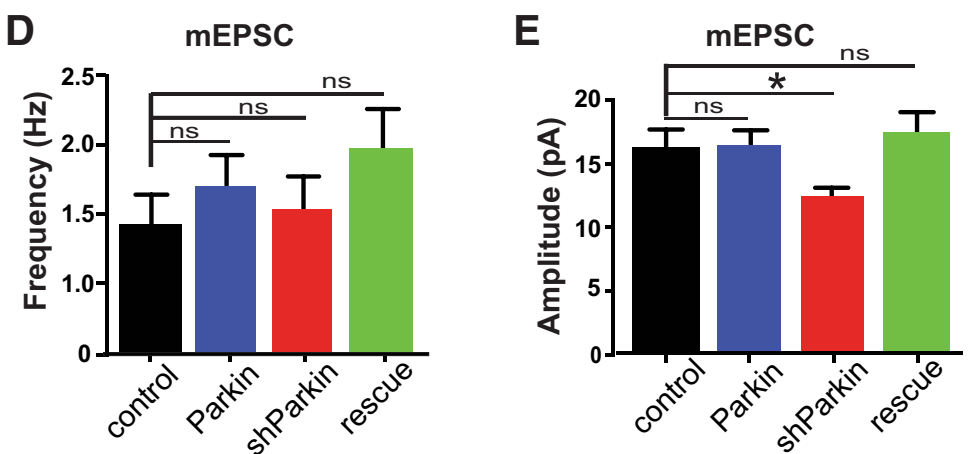

WT

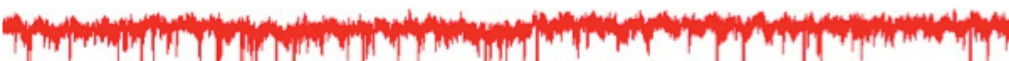

Parkin KO

$$
100 \mathrm{~ms}
$$

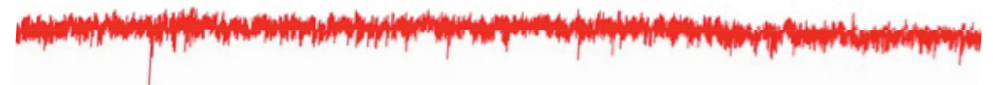

G

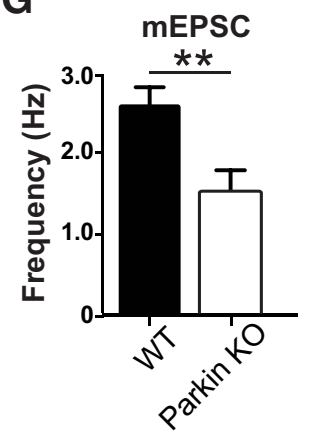

H

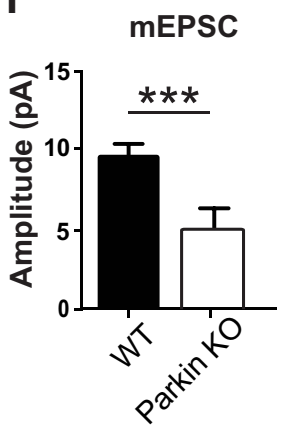


incubated for 40 min with Alexa Fluor 568-conjugated anti-mouse secondary antibody diluted in blocking buffer (used for all remaining steps) to label the recycled surface population of receptors, and washed three times. The remaining surface primary antibodies were blocked with an excess of an unconjugated anti-mouse secondary antibody at room temperature for $30 \mathrm{~min}$, and neurons again were washed four times. After permeabilization, neurons were incubated with Alexa Fluor 647conjugated anti-mouse secondary antibody for $40 \mathrm{~min}$ to label the internalized population of receptors, washed three times, and mounted and imaged as described previously.

Image analyses. All image analyses were performed in a blinded fashion. VAMP2/Homer, VAMP2/SAP102, or Dynamin-3 (Dyn3) puncta density analyses were performed manually in ImageJ/Fiji using the Time Series Analyzer V2 plugin (Balaji) to create ROIs $(8 \times 8$ oval $)$ on immunopositive puncta above a threshold value (determined empirically, typically $<5 \%$ in threshold window) along primary dendrites. The length of primary dendrites was traced using the freehand line tool followed by the "Measure" command, and the average density (number/unit length dendrite) of puncta was calculated for each condition. Intensity analyses were performed by creating a selection using the GFP channel (for soluble GFP or SAP102-GFP); applying it to the relevant GluA1, GluA2, or Homer channels; and measuring average intensity values of GluA1, GluA2, or Homer puncta using the "Analyze Particles" function with puncta size set between 2 and 50 pixels. For internalization and recycling assays, ratios of internalized GluA1 intensity to surface GluA1 intensity, or recycled to internalized GluA1 intensity, were calculated per punctum (after measuring raw intensity values in the red and far-red channels) and averaged for each field of view. These averaged ratios were then normalized to the control condition (average value set to 1) and expressed as a fraction of control. For the GluA1 internalization assay, values $<1$ indicate less efficient AMPA receptor internalization versus control. For the GluA1 recycling assay, values $<1$ indicate less efficient recycling of internalized AMPA receptors back to the plasma membrane versus control.

\section{Results}

\section{Parkin loss of function decreases spontaneous neurotransmission}

We first evaluated the effects of Parkin loss of function on spontaneous excitatory neurotransmission. Rat hippocampal neurons were lentivirally transduced with constructs expressing soluble GFP (control), GFP-tagged human Parkin (Parkin), an shRNA that reduces endogenous Parkin by $\sim 60 \%$ (shParkin; Fig. $1 A, B$ ), or shParkin together with GFP-human-Parkin (rescue; Fig. 1A), which is resistant to shParkin (designed against rat Parkin) and served as a rescue construct. mEPSCs were recorded from 13-15 DIV neurons transduced on 2-3 DIV. Interestingly, neurons expressing shParkin had significantly reduced mEPSC amplitudes $(12.35 \pm 0.75 \mathrm{pA})$ compared with those expressing the control $(16.15 \pm 1.68 \mathrm{pA})$, Parkin $(16.86 \pm 0.89 \mathrm{pA})$, or rescue $(17.84 \pm$ $1.63 \mathrm{pA}$ ) constructs, but no changes in mEPSC frequency (Fig. $1 C-E)$. These results indicated that AMPAR levels and/or activity

\footnotetext{
Figure 1. Loss of Parkin decreases spontaneous excitatory neurotransmission. $A$, Immunoblot of primary hippocampal neurons lentivirally transduced on 2-3 DIV with control, GFP/ shParkin (shParkin), or shParkin + GFP-hu-Parkin (rescue) constructs; collected on 14 DIV; and probed with Parkin, GFP, and tubulin antibodies. $\boldsymbol{B}$, Quantification of shParkin knockdown efficacy, expressed as percentage of endogenous Parkin. Expression of shParkin for $\sim 11 \mathrm{~d}$ led to a $>60 \%$ knockdown of endogenous Parkin ( $n=3$ experiments; ${ }^{* *} p<0.01$, unpaired $t$ test). C, Representative traces of spontaneous mEPSCs from hippocampal neurons transduced on 2-3 DIV with control, GFP-hu-Parkin (Parkin), shParkin, or rescue constructs. $D, E$, Quantification of mEPSC frequency $(\boldsymbol{D})$ and amplitude $(\boldsymbol{E})$ for the four conditions ( $n=16$ for control, 22 for shParkin, 21 for Parkin, 20 for rescue; ${ }^{*} p=0.03$, one-way ANOVA). Error bars represent SEM. $\boldsymbol{F}$, Representative traces of $\mathrm{mEPSC}$ from hippocampal neurons cultured from wild-type and Parkin knock-out rats. $\boldsymbol{G}, \boldsymbol{H}$, Quantification of mEPSC frequency $(\boldsymbol{G})$ and amplitude $(\boldsymbol{H})$ for the two conditions ( $n=15$ for WT, 31 for Parkin K0; ${ }^{* *} p=0.004,{ }^{* * *} p<0.0001$, one-way ANOVA). Error bars represent SEM.
}

were reduced in Parkin-deficient neurons. Because these findings contradicted those from a previous study (Helton et al., 2008), we further investigated spontaneous neurotransmission in hippocampal neurons isolated from Parkin knock-out rats (SAGE Labs/Horizon Discovery). In agreement with our knockdown findings, we observed a significant reduction in mEPSC amplitude in $\mathrm{KO}$ neurons $(5.48 \pm 0.25 \mathrm{pA})$ compared with wild-type controls (9.68 \pm 0.57 pA; Fig. $1 F, H)$. Unexpectedly, we also saw a significant reduction in mEPSC frequency (WT, $2.48 \pm 0.36$ $\mathrm{Hz}$; Parkin KO, $1.54 \pm 0.13 \mathrm{~Hz}$; Fig. $1 F, G)$, likely reflecting presynaptic effects of Parkin loss of function, which have been reported in studies of Parkin knock-out mice (Itier et al., 2003; Hanson et al., 2010). However, since our initial findings indicated a striking postsynaptic phenotype for Parkin knockdown, we focused our remaining experiments on its role in the postsynaptic compartment.

Parkin knockdown was previously reported to increase glutamatergic synapse formation (Helton et al., 2008), so we measured the density of synapses on primary dendrites of pyramidal neurons transduced with control, shParkin, or rescue constructs on 2-3 DIV and fixed on 14-15 DIV. The average density (number/ unit length dendrite) of VAMP2/Homer1-positive synapses was calculated for each condition and found to be comparable (Fig. $2 A, C)$, indicating that Parkin deficiency does not affect excitatory synapse number in our cultures. However, because postsynaptic Homer1 levels appeared to be reduced in dendrites of shParkin neurons (Fig. 2A; see also Fig. 5), we confirmed these findings with another excitatory postsynaptic protein, SAP102. Here, SAP102-GFP was lentivirally expressed alone or together with shParkin from 3-14 DIV, and the density of SAP102-GFP/ VAMP2-positive puncta was calculated as before. Again, we found no difference in synapse density between control and Parkin-deficient neurons (Fig. $2 B, D$ ).

\section{Parkin deficiency reduces synaptic efficacy and cell-surface AMPARs}

To further investigate Parkin's role in postsynaptic glutamatergic transmission, we performed paired-cell recordings in cultures of 5-10 hippocampal neurons plated onto glial microislands, a preparation that ensures high connectivity between neurons. Neurons were lentivirally transduced with one of the four constructs on 2-3 DIV, and eEPSCs were recorded on 13-15 DIV from pairs in which the postsynaptic (recording) cell was lentivirally transduced whereas the presynaptic (stimulating) cell was untransduced (Fig. 3A). This configuration allowed us to isolate Parkin's postsynaptic function. Strikingly, we found that shParkin-expressing neurons had significantly decreased eEPSC amplitudes (36.98 $\pm 4.44 \mathrm{pA}$ ) compared with those expressing the control $(302.9 \pm 113.4 \mathrm{pA})$, Parkin $(299.1 \pm 68.71 \mathrm{pA})$, or rescue $(264.8 \pm 80.44$ pA) constructs (Fig. $3 B, C$ ). Furthermore, shParkin neurons had a threefold increase in the number of postsynaptic failures after presynaptic stimulation compared with the other conditions, indicating a dramatic decrease in synaptic efficacy (Fig. 3D,E).

An increased rate of synaptic failures can be caused by decreased presynaptic neurotransmitter release probability or decreased postsynaptic glutamate receptor number. To investigate the latter possibility, we measured whole-cell currents induced by local application of kainate to stimulate cell-surface AMPARs. Kainate application induced robust AMPAR-mediated currents in neurons expressing control (139.8 $\pm 35.6 \mathrm{pA})$ or rescue $(413.0 \pm 26.0 \mathrm{pA})$ constructs, and these were dramatically in- 
A

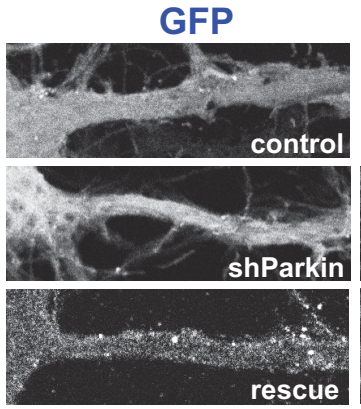

B
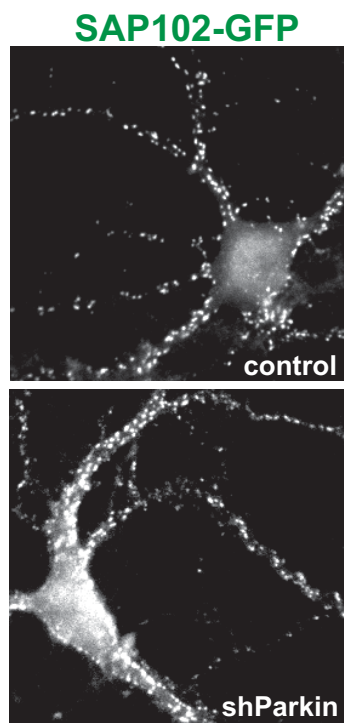

C

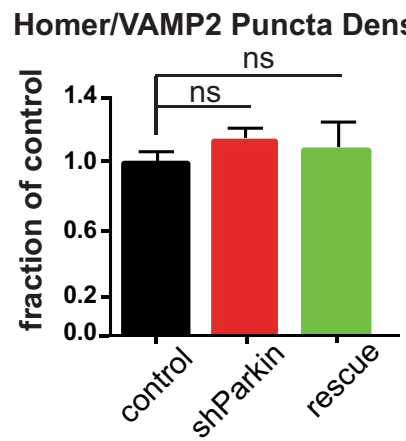

VAMP2
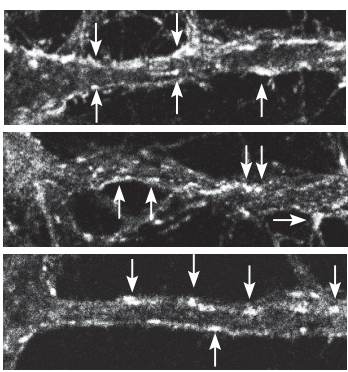

Homer

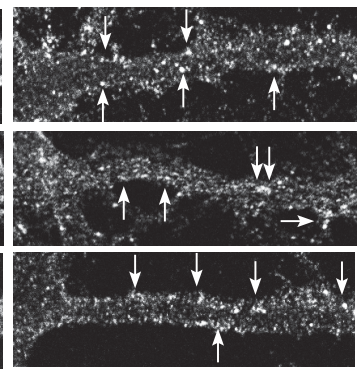

merge

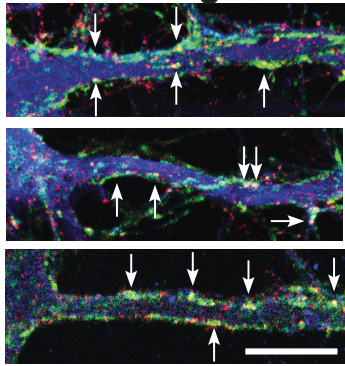

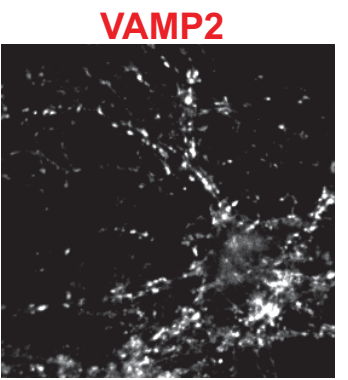
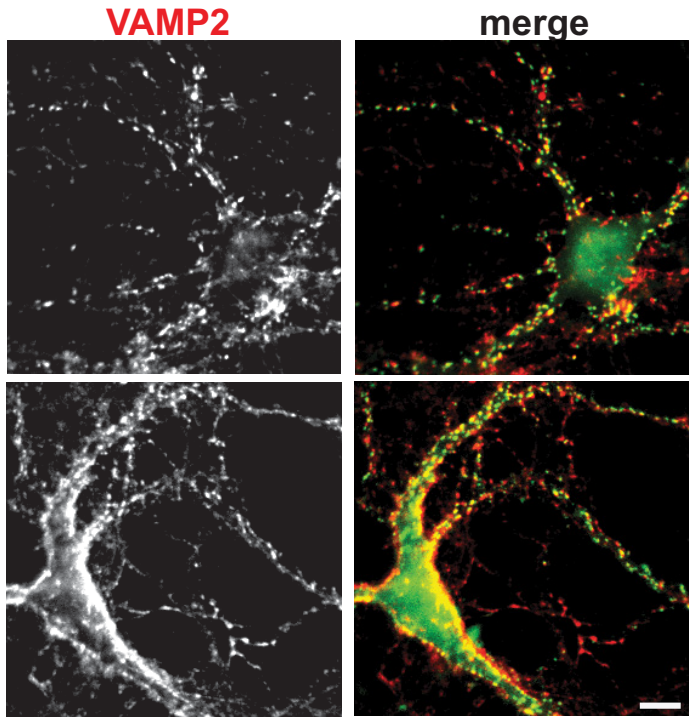

D

SAP102/VAMP2 Puncta Density

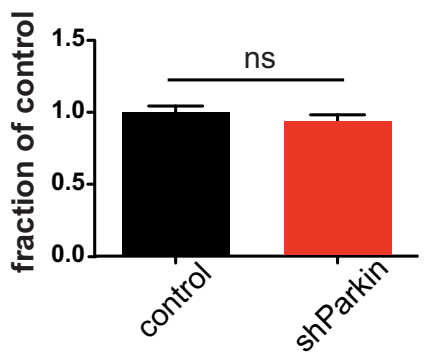

Figure 2. Synapse density is unaltered by Parkin knockdown. $A$, Images of 15 DIV hippocampal neurons expressing control, shParkin, or rescue constructs and immunostained for VAMP2 and Homer to label excitatory synapses. Scale bar, $10 \mu \mathrm{m}$. B, Images of 15 DIV hippocampal neurons expressing SAP102-GFP+ / - shParkin (green) and immunostained for VAMP2 (red). Scale bar, 10 $\mu \mathrm{m}$. C, Quantification of synapse density, measured as VAMP2/Homer-immunopositive puncta/unit length primary dendrite and expressed as a fraction of control condition ( $n \geq 5$ fields of view per condition with $>100$ VAMP2/Homer puncta per field, results confirmed in 3 independent experiments; no significant differences, unpaired $t$ test). Error bars represent SEM. $\boldsymbol{D}$, Quantification of synapse density, measured as in $C$ ( $n \geq 5$ fields of view per condition with $>100$ VAMP2/SAP102 puncta per field, results confirmed in 3 independent experiments; no significant differences, unpaired $t$ test). Error bars represent SEM.

creased by overexpression of Parkin $(1395 \pm 127.4 \mathrm{pA}$; Fig. $4 A, B)$. In contrast, shParkin-expressing neurons exhibited a greater than twofold reduction in AMPAR-mediated currents compared with controls $(67.7 \pm 13.1$ pA; Fig. $4 A, B)$. These data indicate a postsynaptic origin for the high failure rates observed in Parkin-deficient neurons, although we cannot rule out a presynaptic contribution to this phenotype. However, given that all presynaptic inputs in our preparation derive from wild-type neurons, any changes in neurotransmitter release probability would presumably result from retrograde signals emanating from the Parkin-deficient postsynaptic compartment.

To directly measure cell-surface AMPAR levels, we performed immunostaining with antibodies against the AMPAR subunits GluA1 and GluA2. We found that the cell-surface levels of both subunits were significantly reduced (by $25 \%$ for GluA1, 20\% for GluA2) in neurons expressing shParkin compared with control or rescue constructs (Fig. 4C-E). To verify that the synaptic pools of surface AMPARs were similarly reduced, we performed surface GluA1 immunostaining of neurons expressing SAP102- 
A
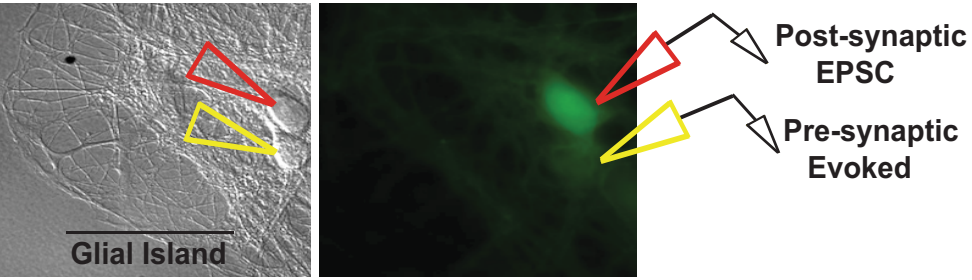

B
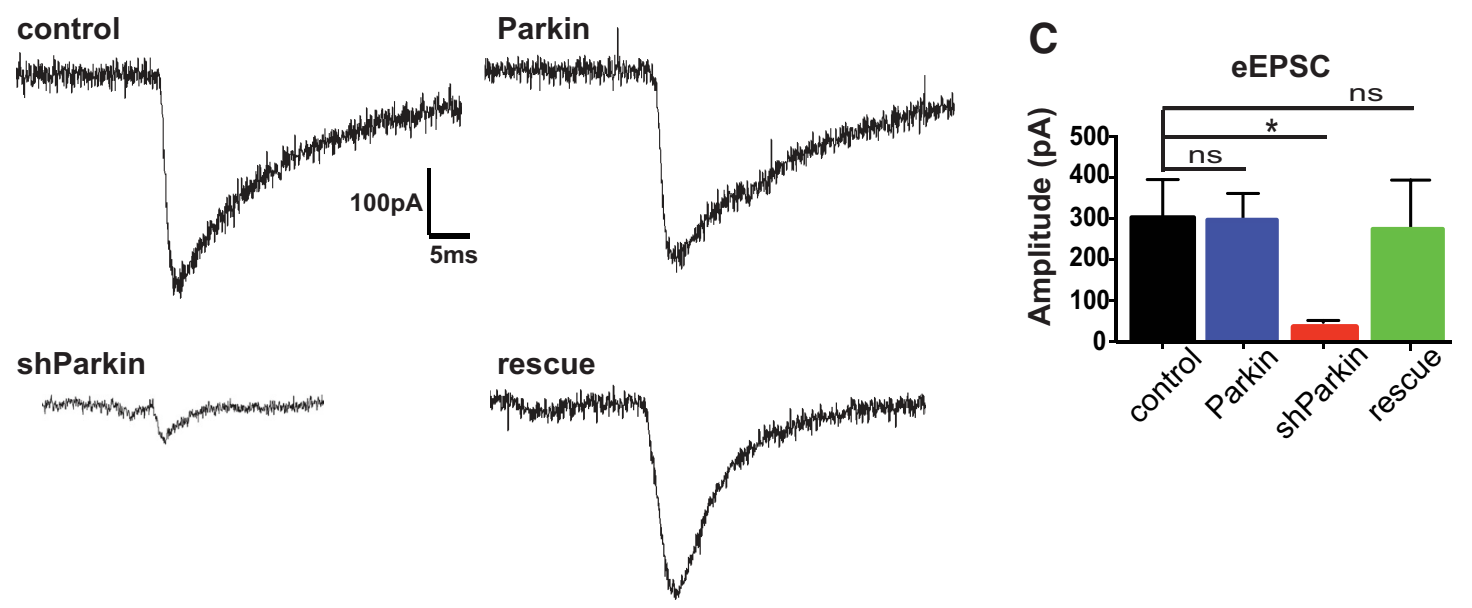

D

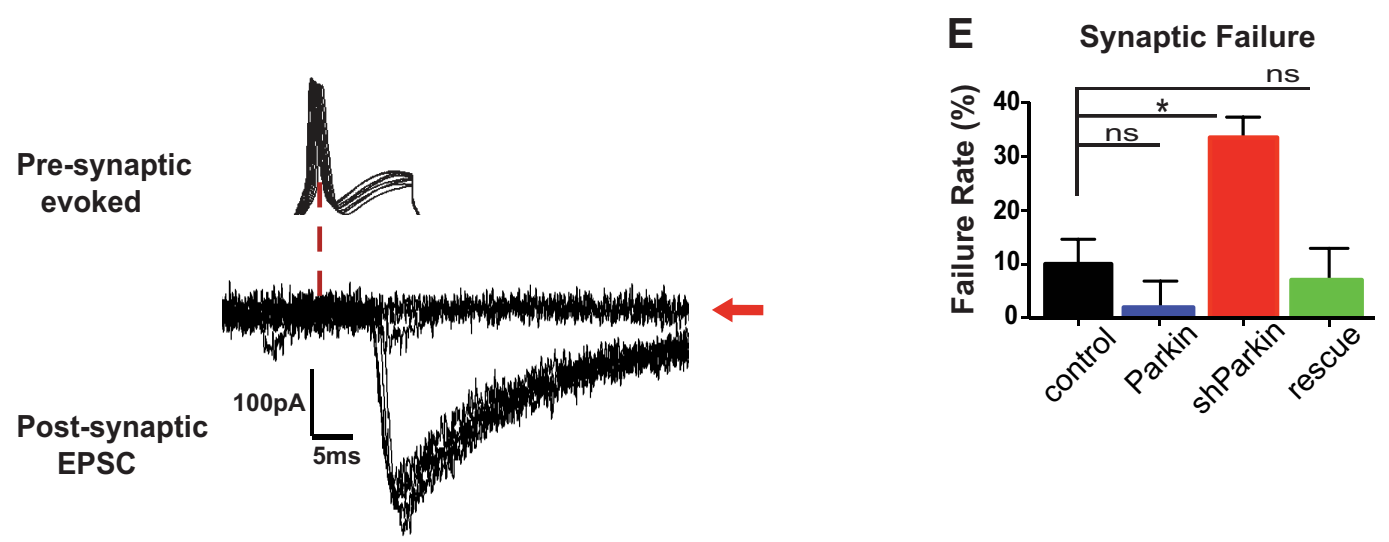

Figure 3. Parkin deficiency reduces synaptic efficacy. $A, \mathrm{DIC}$ (left) and fluorescence images of hippocampal neurons cultured on glial microislands, illustrating the recording paradigm. Presynaptic stimuli were evoked in untransduced neurons, and postsynaptic responses were recorded from neurons transduced with one of the four constructs. $\boldsymbol{B}$, Representative traces of evoked EPSCs from neurons expressing the construct indicated. C, Quantification of eEPSC amplitude ( $n=18$ cells for GFP control, 14 for shParkin, 15 for Parkin, 6 for rescue; ${ }^{*} p=0.04$, one-way ANOVA). Error bars represent SEM. D, Example of synaptic failures over a $10 \mathrm{~s}$ recording trial at $1 \mathrm{~Hz}$. Positive current at action potential threshold produced action potentials in the presynaptic cell (top). A postsynaptic cell held at $-70 \mathrm{mV}$ generated eEPSCS or synaptic failures (indicated by red arrow). $E$, Quantification of EPSC failure rate ( $n=18$ for control, 14 for shParkin, 15 for Parkin, 6 for rescue; ${ }^{*} p=0.04$, one-way ANOVA). Error bars represent SEM.

GFP+/ - shParkin (Fig. 4F). Again, the average intensity of GluA1 puncta colocalizing with SAP102-GFP was reduced by nearly $30 \%$ (Fig. $4 F, G$ ), consistent with synaptic loss of surface AMPARs. These findings suggest that Parkin is a positive regulator of cell-surface AMPAR expression.

Parkin regulates Homer1 levels at the PSD

Parkin was previously shown to localize to PSDs and coimmunoprecipitate with a complex of PSD proteins, including CASK, PSD-95, and Homer1, indicating that it is a molecular component of the PSD (Fallon et al., 2002). To investigate whether loss of Parkin alters the protein composition of the PSD, we performed quantitative immunoblotting of purified PSDs isolated from whole brains of wild-type and Parkin KO rats. Although the levels of PSD-95, CaMKII, and GluA2/3 were unchanged in PSDs from $\mathrm{KO}$ animals versus wild-type controls, those of Homer $1 \mathrm{~b} / \mathrm{c}$, CASK, and GluA1 were significantly decreased (Fig. $5 A, B$ ). These differences were not seen in PSDs isolated from PINK1 knockout rats (Fig. 5A, C), indicating that the changes in PSD composition were specific to Parkin loss of function and did not depend on the kinase PINK1, which is required for Parkin activation upstream of mitophagy (Wang et al., 2011; Caulfield et al., 2015). 
A

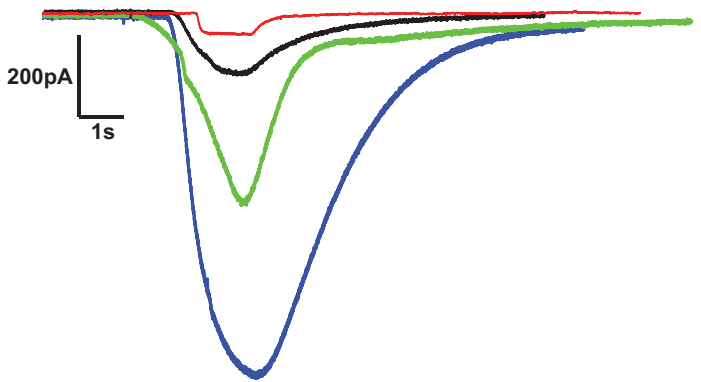

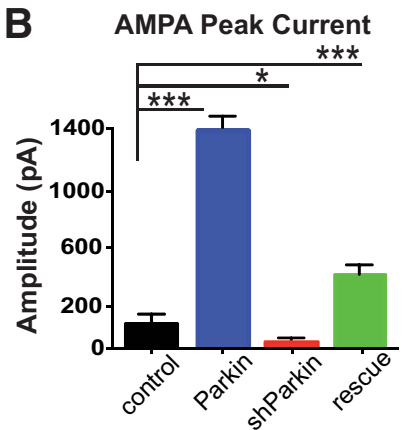

C
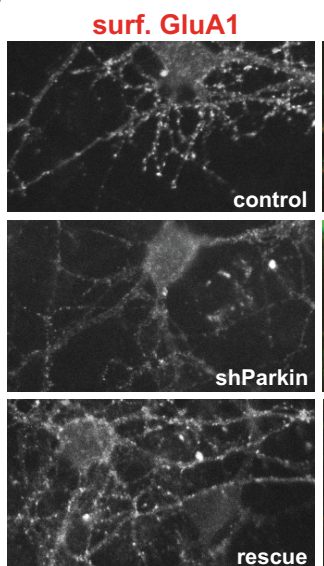

D Surface GluA1 Intensity

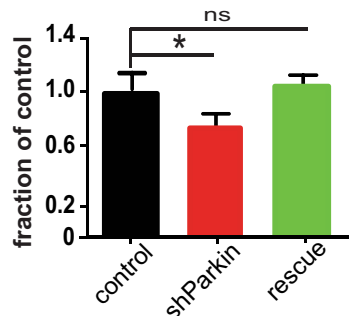

$\mathbf{F}$
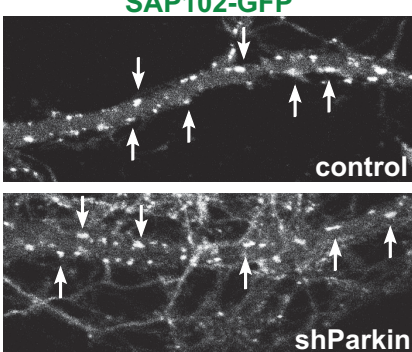

merge
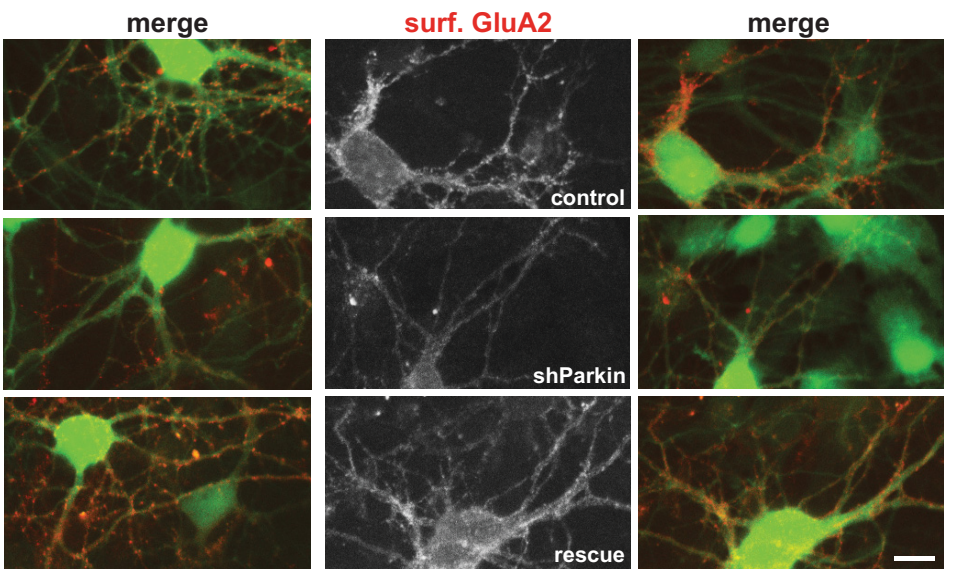

E Surface GluA2 Intensity

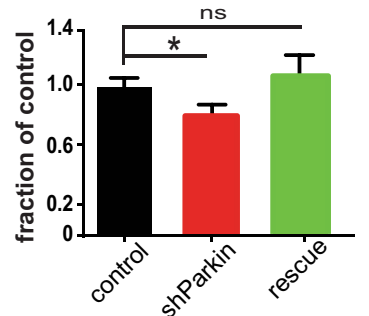

\section{G Synaptic surface GluA1}

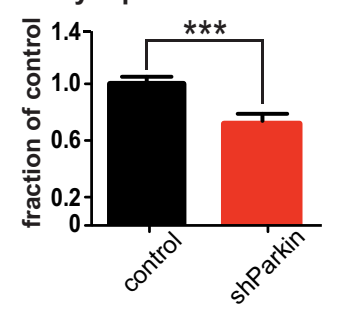

Figure 4. Parkin deficiency decreases cell-surface AMPA receptor levels. $A$, Representative traces of whole-cell currents induced by local application of $100 \mu \mathrm{m}$ kainate for neurons expressing control, Parkin, shParkin, or rescue constructs. B, Quantification of peak current amplitudes induced by AMPA receptor activation ( $n=17$ for control, 27 for shParkin, 13 for Parkin, 10 for rescue; ${ }^{*} p=0.03,{ }^{* * *} p<0.0001$, one-way ANOVA). Error bars represent SEM. C, Images of 15 DIV neurons expressing control, shParkin, or rescue constructs (all green) immunostained for cell-surface GluA1 or GluA2 (red). Scale bar, $10 \mu \mathrm{m}$. D, Quantification of cell-surface GluA1, expressed as a fraction of control ( $n \geq 5$ fields of view per condition with $>50$ GluA1 puncta per field, results confirmed in 3 independent experiments; ${ }^{*} p<0.05$, unpaired $t$ test). Error bars represent SEM. E, Quantification of cell-surface GluA2, expressed as a fraction (Figure legend continues.) 
Since Homer 1 levels were the most significantly decreased by Parkin knock-out, we next assessed whether these changes could be detected in Parkin-deficient hippocampal neurons by immunofluorescence microscopy. Here, we performed quantitative immunostaining of Homer 1 in 15 DIV neurons expressing the control, shParkin, or rescue constructs. We found that the average intensity of postsynaptic Homer1 puncta was decreased by nearly $40 \%$ in shParkin-expressing neurons compared with the control and rescue conditions (Fig. $5 D, E$ ). This decrease, also observed in our previous experiments (Fig. 2A), demonstrates that Parkin is essential for maintaining Homer1 levels in the PSD.

Homer 1 is a member of the Homer family of adaptor proteins, which have important roles in postsynaptic protein scaffolding, signal transduction, and synaptic plasticity (Shiraishi-Yamaguchi and Furuichi, 2007). Homer1 is known to facilitate the postsynaptic clustering and signaling of metabotropic glutamate receptor type 5 (mGluR5; Marton et al., 2015), and we hypothesized that its loss from synapses could be responsible for the reduction in synaptic AMPARs in Parkin-deficient neurons. To test this hypothesis, we overexpressed Homer1 in Parkin knockdown neurons, cotransfecting GFP-Homer 1 with mCherry + / - shParkin on $5 \mathrm{DIV}$, then fixing and immunostaining for surface GluA1 on DIV 15. The intensity of cell-surface GluA1 was measured and compared between these conditions. Remarkably, we found that overexpression of GFP-Homer1 did not significantly alter surface GluA1 levels in control neurons but completely normalized GluA1 levels in shParkin-expressing neurons (Fig. 6A, B). These findings indicate that the loss of postsynaptic Homer 1 is primarily responsible for the decrease in surface AMPARs observed after Parkin loss of function. To determine whether Homer1 and Parkin can directly interact, we performed coimmunoprecipitation experiments in HEK293T cells transfected with Myc-tagged Parkin and either soluble GFP or GFP-Homer1. We found that GFPHomer1 was efficiently immunoprecipitated by Myc-Parkin (Fig. 6C), indicating that these proteins can interact in the absence of other PSD proteins such as PSD-95 and CASK, and suggesting that Parkin stabilizes Homer1 in the PSD through a direct binding interaction.

\section{Parkin deficiency disrupts postsynaptic endocytic zones}

Homer1 was previously found to be necessary for positioning postsynaptic EZs for AMPAR internalization adjacent to PSDs, via its interactions with the endocytic GTPase Dynamin-3 (Lu et al., 2007; Petrini et al., 2009). Disruption of the Homer1/Dyn3 interaction was shown to uncouple EZs from the PSD, thereby reducing synaptic AMPAR levels by preventing their efficient capture, internalization, and reinsertion at the PSD membrane (Lu et al., 2007). Since we observed a loss of synaptic cell-surface AMPARs, decreased AMPAR-mediated neurotransmission, and significantly reduced postsynaptic Homer1 levels in Parkindeficient neurons, we tested whether EZs were disrupted by Parkin loss of function. EZs were visualized by cotransfecting neurons with HA-tagged Dyn3 and SAP102-GFP+/- shParkin on 5 DIV, followed by fixation and image acquisition on 15 DIV.

\section{$\leftarrow$}

(Figure legend continued.) of control ( $n \geq 4$ fields of view per condition with $>50 \mathrm{GluA2}$ puncta per field, results confirmed in 3 independent experiments; ${ }^{*} p<0.05$, unpaired $t$ test). Error bars represent SEM. $\boldsymbol{F}$, Images of 15 DIV neurons expressing SAP102-GFP + / - shParkin immunostained for cell-surface GluA1. Scale bar, $10 \mu \mathrm{m}$. G, Quantification of synaptic cellsurface GluA1 based on colocalization with SAP102-GFP, expressed as a fraction of control ( $n \geq$ 6 fields of view per condition with $>50 \mathrm{GluA} 1$ puncta per field, results confirmed in 3 independent experiments; ${ }^{* * *} p<0.0001$, unpaired $t$ test).
In control neurons, we found that nearly 50\% of SAP102-GFP puncta colocalized with HA-Dyn3, indicating coupling between PSD and EZ components. This colocalization was reduced by $\sim 15 \%$ in shParkin-expressing neurons (from $46 \%$ to $30 \%$; Fig. $7 A, B)$. Moreover, the density of HA-Dyn3 puncta/unit length dendrite was reduced by $40 \%$ in shParkin neurons compared with controls (Fig. $7 \mathrm{~A}, \mathrm{C}$ ). We repeated these experiments in hippocampal neurons isolated from wild-type and Parkin $\mathrm{KO}$ rats and obtained similar results (Fig. 7D-F). In Parkin KO neurons, colocalization of SAP102-GFP with HA-Dyn3 was reduced by $17 \%$ (from $52 \%$ to $35 \%$; Fig. $7 \mathrm{D}, E$ ), and Dyn 3 puncta density by nearly $40 \%$ (Fig. 7D,F). We also confirmed that the density of SAP102-GFP puncta was unchanged between wild-type and $\mathrm{KO}$ neurons (Fig. $7 D, G$ ) and that Parkin expression was completely absent from our KO cultures (Fig. $7 \mathrm{H}$ ), again demonstrating that Parkin loss of function does not alter synapse formation. Since Parkin has been found to interact with several endocytic proteins (e.g., endophilin-A, Eps15; Fallon et al., 2006; Trempe et al., 2009), we used our HEK293T cell coimmunoprecipitation assay to determine whether it could similarly interact with HA-Dyn3. In contrast to Homer1, we did not observe any binding of Parkin to HA-Dyn3 in HEK cell lysates (Fig. 7I). These findings demonstrate that both acute and chronic Parkin loss significantly decrease EZ density, most likely through reduced tethering of EZs to the PSD via Parkin/Homer1 and Homer1/Dyn3 interactions.

\section{Parkin deficiency impairs AMPAR endocytosis but not recycling}

Since the loss of EZs was previously shown to impair AMPAR internalization (Lu et al., 2007), we next evaluated whether this phenotype was present in Parkin-deficient neurons. Here, we used an antibody feeding assay to monitor the internalization of endogenous GluA1 in control and shParkin-expressing neurons over a 15-30 min time period. After primary antibody labeling for $40 \mathrm{~min}$ at $25^{\circ} \mathrm{C}$, neurons were incubated for 15 or $30 \mathrm{~min}$ at $37^{\circ} \mathrm{C}$ to allow for receptor internalization, then fixed and incubated with Alexa Fluor 568-conjugated secondary antibody to label cell-surface GluA1, and finally permeabilized and incubated with Alexa Fluor 647-conjugated secondary antibody to label internalized GluA1 (Fig. $8 A$ ). The ratio of internalized to surface GluA1 was calculated for control and shParkin-expressing neurons at both time points and normalized to the average values obtained for control neurons (Fig. $8 B, C$ ). We found that the internalized/surface ratio of GluA1 was reduced by $25 \%$ at the 15 min time point and by $15 \%$ at the 30 min time point, indicating that AMPAR internalization was significantly impaired in Parkin-deficient neurons.

To determine whether the recycling of internalized AMPARs back to the cell surface was also disrupted by Parkin loss of function, we used another antibody feeding assay to evaluate endogenous GluA1 recycling in control and Parkin knockdown neurons. Here, surface receptors were labeled with primary antibody as before and allowed to internalize for $30 \mathrm{~min}$ at $37^{\circ} \mathrm{C}$. After this time period, the remaining surface-associated antibody was blocked with an unlabeled secondary antibody, and neurons were subsequently incubated for $1 \mathrm{~h}$ at $37^{\circ} \mathrm{C}$ to allow for receptor recycling back to the cell surface. Neurons were then fixed and incubated with Alexa Fluor 568-conjugated secondary antibody to label recycled cell-surface receptors, and finally permeabilized and incubated with Alexa Fluor 647-conjugated secondary antibody to label internalized receptors (Fig. $8 D$ ). The ratio of recycled to internalized GluA1 was calculated for control and shParkin-expressing neurons and normalized to the average val- 
A

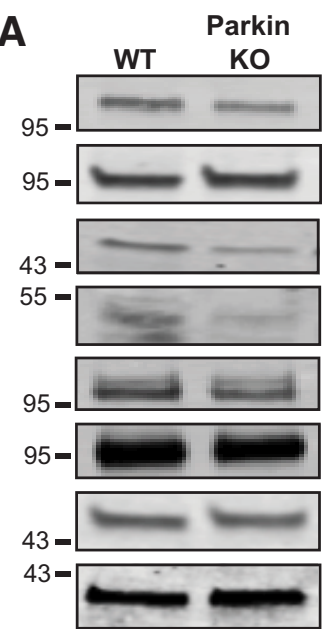

B

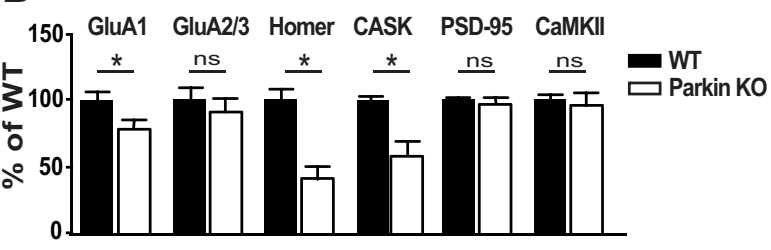

C

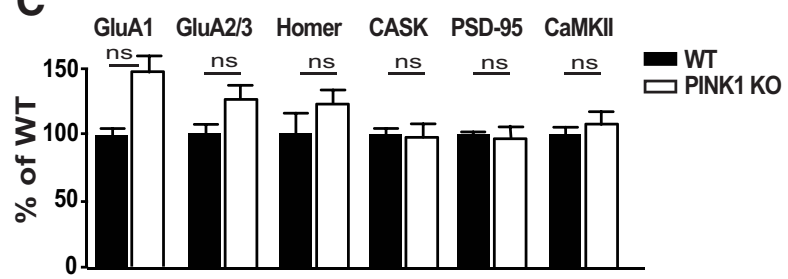

D

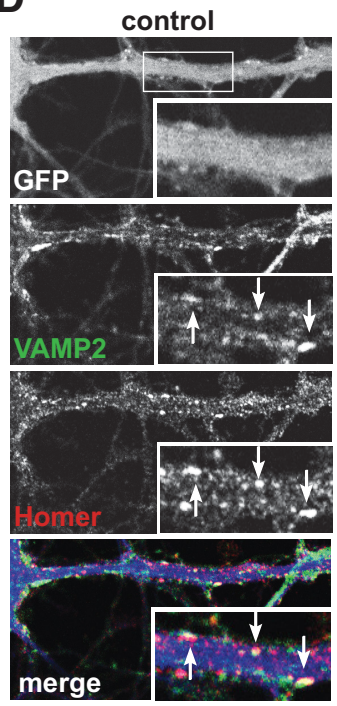

shParkin
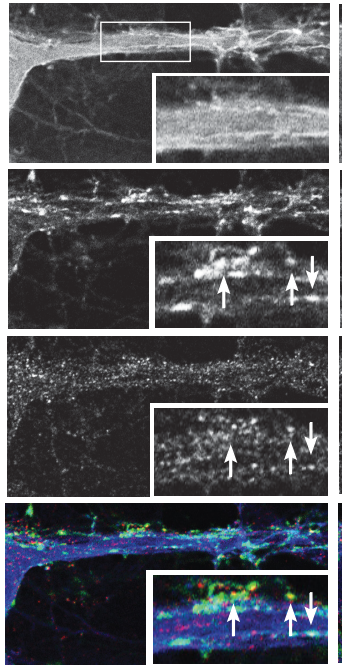
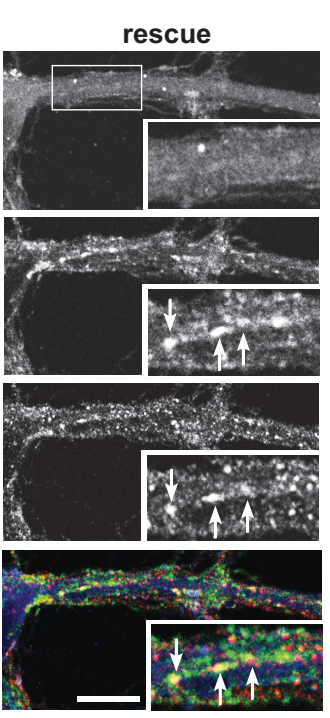

E Synaptic

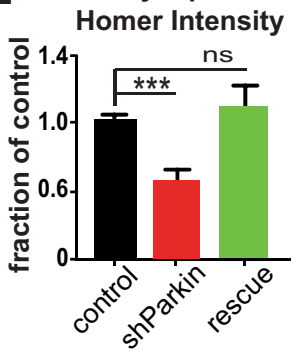

Figure 5. Altered postsynaptic density composition in Parkin KO neurons. $A$, Left, Immunoblots of purified PSDs from whole brain of WT or Parkin K0 rats, probed for the indicated proteins ( $n=3$ animals per condition). Right, Immunoblots of PSDs from whole brain of WT or PINK1 KO rats, probed for the indicated proteins ( $n=2$ animals per condition). The black vertical line on the Parkin immunoblot indicates that these lanes are not contiguous. B, Quantification of PSD protein levels for WT and Parkin KO conditions, normalized to GAPDH and expressed as percentage of mean WT protein level $\left({ }^{*} p<0.05\right.$, unpaired $t$ test). Error bars represent SEM. C, Quantification of PSD protein levels for WT and PINK1 K0 conditions, normalized to GAPDH and expressed as percentage of mean WT protein level. Error bars represent SEM. D, Images of 15 DIV hippocampal neurons expressing control, shParkin, or rescue constructs and immunostained for Homer1 and VAMP2. Arrows indicate representative synaptic Homer1 puncta (based on colocalization with VAMP2) for each condition. White rectangular boxes indicate magnified regions for insets. Scale bars, $10 \mu \mathrm{m}$ for both larger images (white) and insets (black). $E$, Quantification of Homer1 intensity at synapses, defined as Homer1/VAMP2-immunopositive puncta along dendrites (as in Fig. 2), expressed as a fraction of control ( $n \geq 5$ fields of view per condition with $>100$ VAMP2/Homer1 puncta per field, results confirmed in 3 independent experiments; ${ }^{* * *} p<0.001$, unpaired $t$ test). 
A
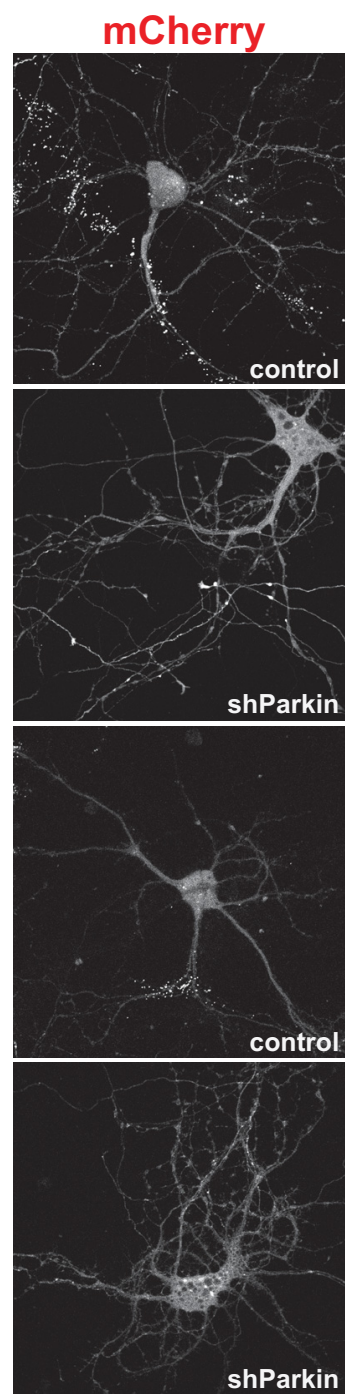

shParkin

B

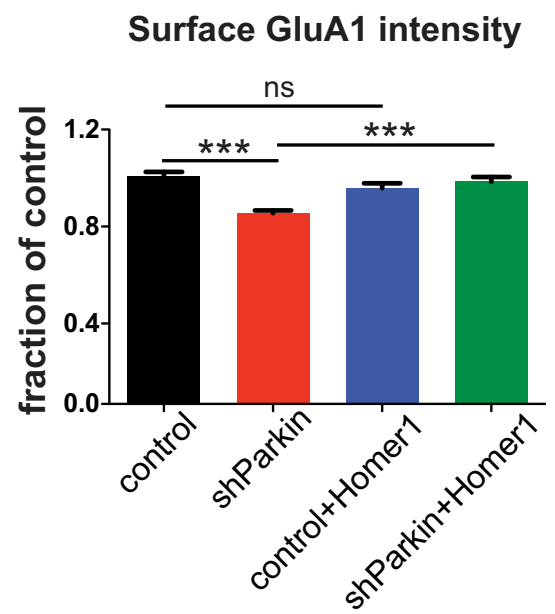

GFP-Homer1
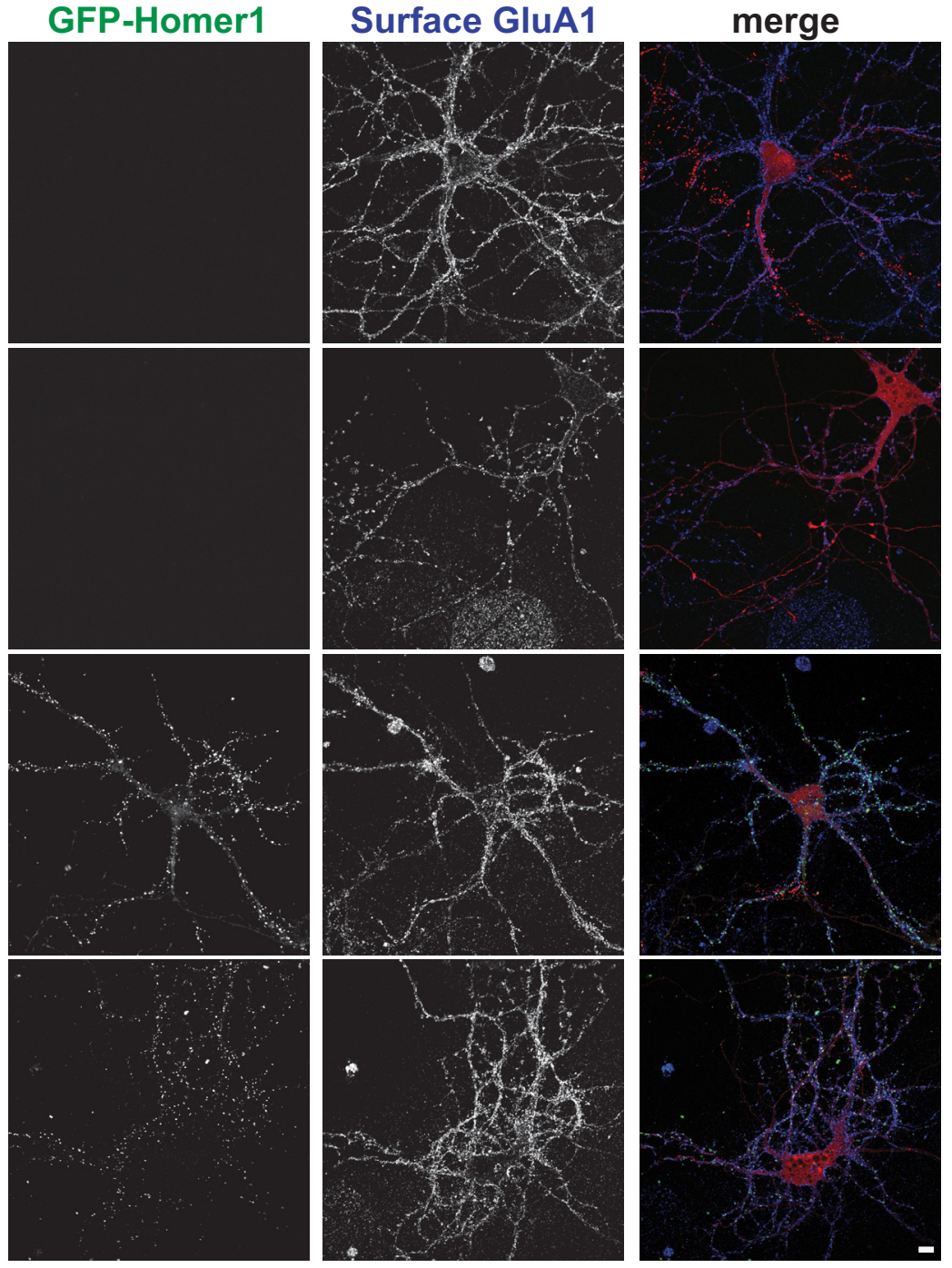

C

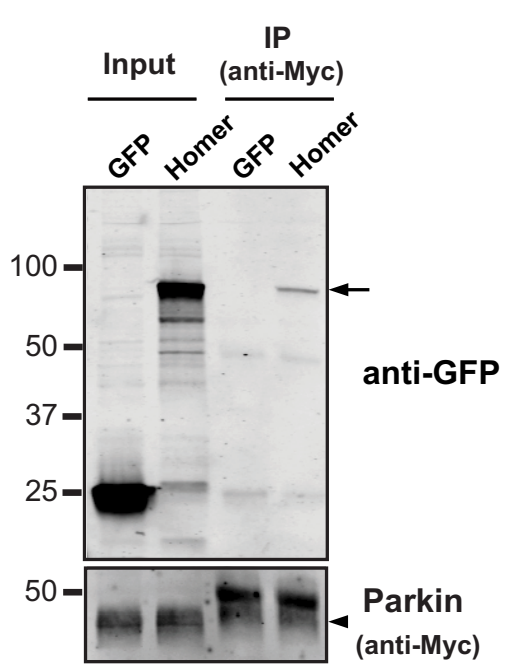

Figure 6. Homer1 overexpression rescues cell-surface GluA1 in Parkin-deficient neurons. A, Images of 15 DIV hippocampal neurons cotransfected with $\mathrm{mCherry}+/-$ shParkin alone or with GFP-Homer1 and immunostained for surface GluA1. Scale bar, $10 \mu \mathrm{m}$. B, Quantification of cell-surface GluA1, expressed as a fraction of mCherry control ( $n \geq 20$ fields of view per condition with $>50$ GluA1 puncta per field, results confirmed in 2 independent experiments; ${ }^{* * *} p<0.0001$, unpaired $t$ test). Error bars represent SEM. C, Immunoblot of lysates from HEK293T cells expressing Myc-Parkin and either soluble GFP or GFP-Homer1, immunoprecipitated (IP) with Myc antibody, and probed with Myc or GFP antibodies. The arrow indicates GFP-Homer1, and the arrowhead indicates Myc-Parkin (just below IgG band). 
D

A
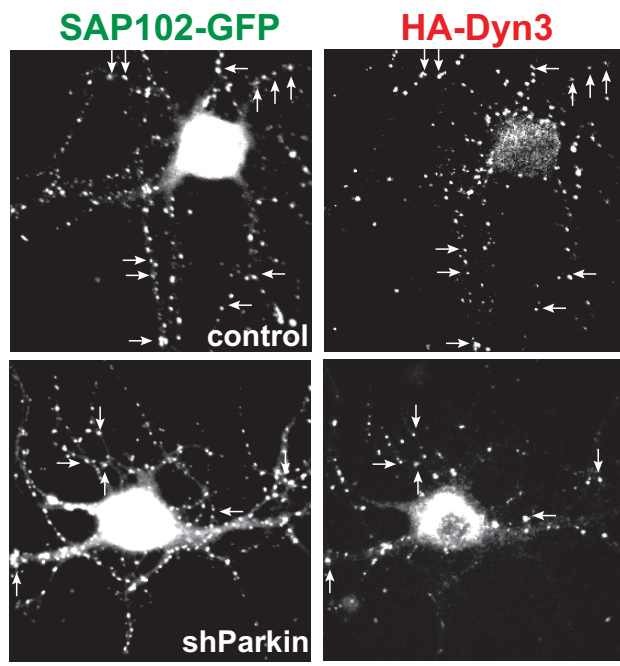
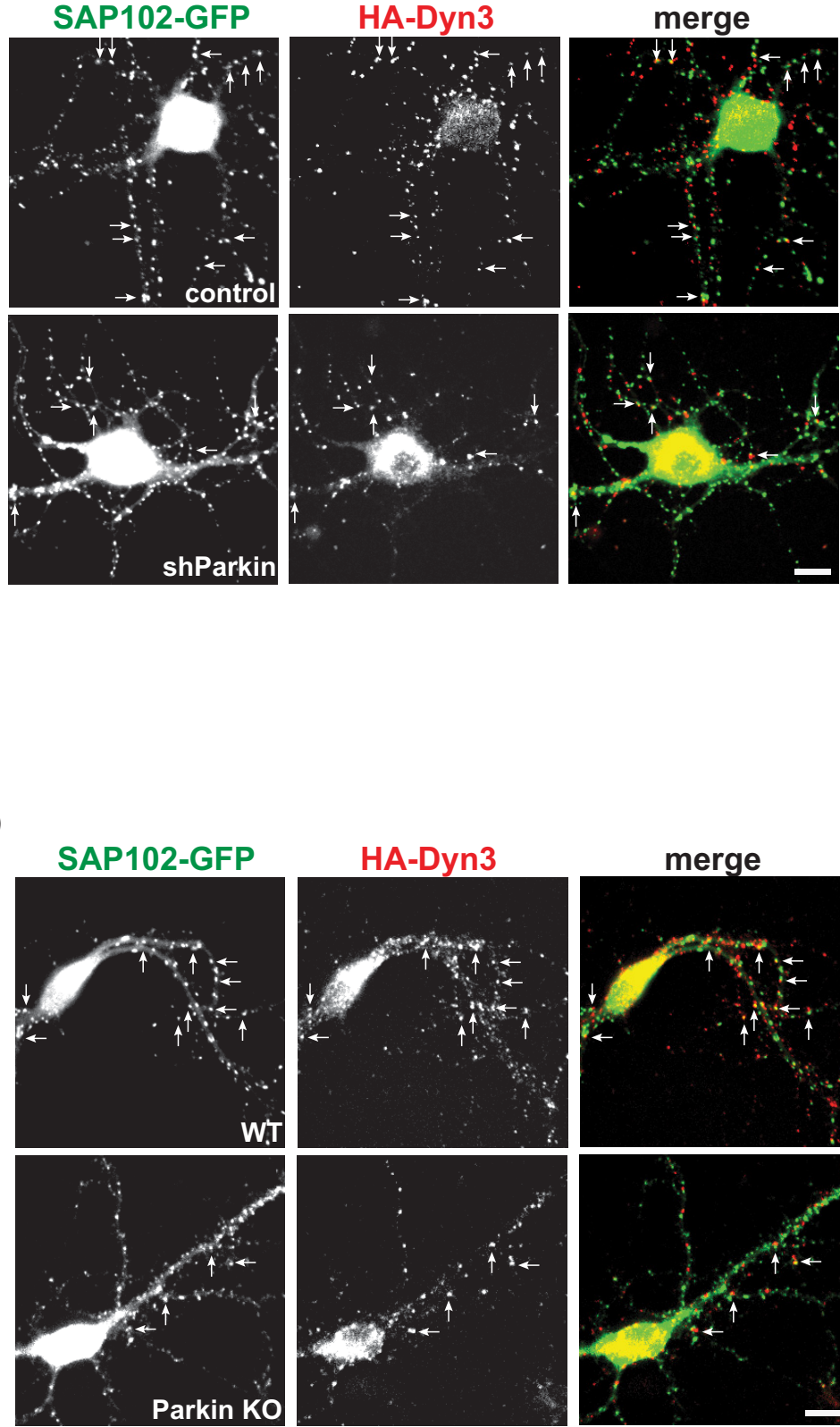

B

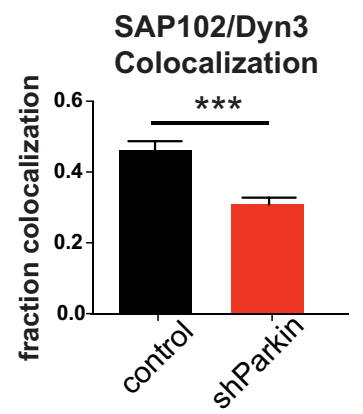

C

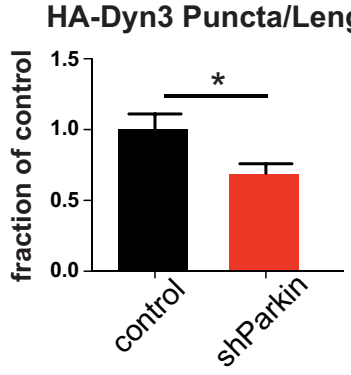

E
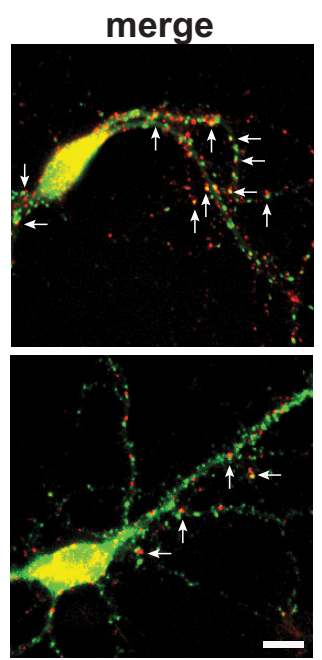

G

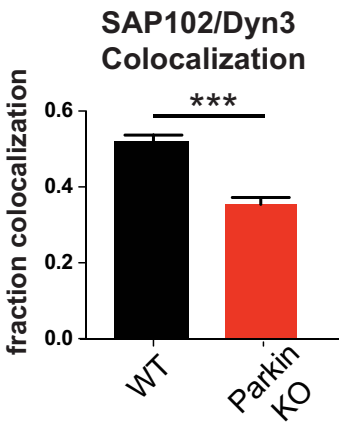

F

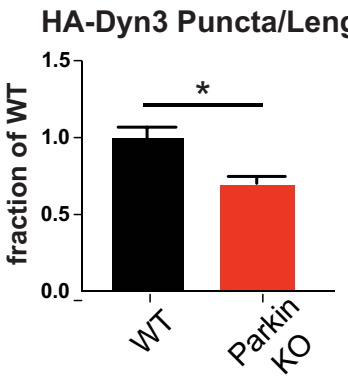

SAP102 Puncta/Length
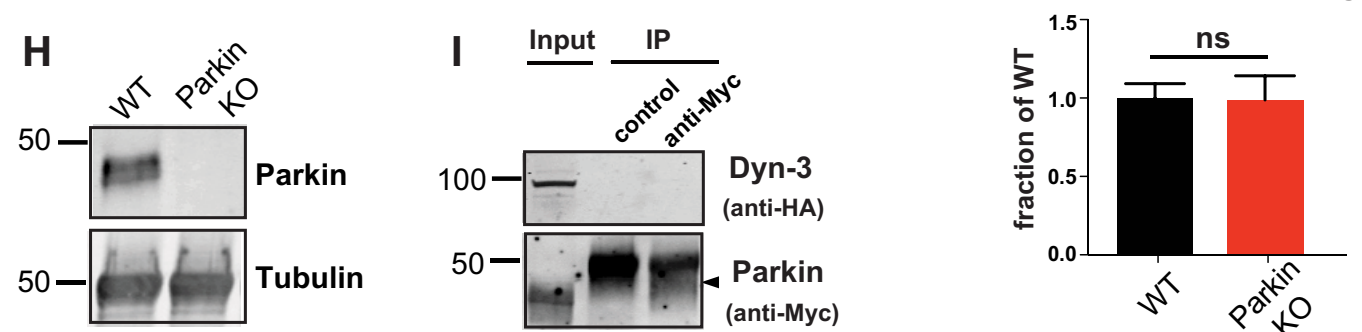

Figure 7. Reduced endocytic zone density in Parkin-deficient neurons. $\boldsymbol{A}$, Images of 15 DIV hippocampal neurons cotransfected with SAP102-GFP $+/-$ shParkin (green) and HA-Dynamin-3 (red). Arrows indicate colocalized puncta. Scale bar, $10 \mu \mathrm{m}$. B, Quantification of SAP102/Dynamin-3 colocalization ( $n \geq 20$ fields of view per condition from 3 independent experiments, $30-100$ SAP102 puncta/field; ${ }^{* * *} p<0.001$, unpaired $t$ test). C, Quantification of Dynamin-3 puncta/unit length dendrite, expressed as a fraction of control ( $n \geq 20$ fields of view per condition from 3 independent experiments, $20-120$ HA-Dynamin puncta per field; ${ }^{*} p<0.05$, unpaired $t$ test). D) Images of 15 DIV hippocampal neurons from WT and K0 rats, cotransfected with SAP102-GFP and HA-Dynamin-3. Arrows indicate colocalized puncta. Scale bar, $10 \mu \mathrm{m}$. E, Quantification of SAP102/Dynamin-3 colocalization ( $n \geq 11$ fields of view, $30-150$ SAP102 puncta per field; *** $p<0.001$, unpaired $t$ test). $\boldsymbol{F}$, Quantification of Dynamin-3 puncta/unit length dendrite, expressed as a fraction of wild-type control ( $n \geq 11$ fields of view, $15-115 \mathrm{HA}$-Dynamin puncta per field; ${ }^{*} p<0.05$, unpaired $t$ test). G, Quantification of SAP102 puncta/unit length dendrite, expressed as a fraction of wild-type control ( $n \geq 11$ fields of view, $30-150$ SAP102 (Figure legend continues.) 
ues obtained for control neurons (Fig. $8 E$ ). Surprisingly, we did not see any difference in these ratios for control and Parkindeficient neurons (Fig. 8E), suggesting that the recycling of AMPARs was not altered by Parkin loss of function. These findings indicate that the phenotypes observed at excitatory synapses lacking Parkin (reduced AMPAR-mediated currents and cellsurface expression, increased synaptic failure rate) are due to reduced EZ density, leading to inefficient cell-surface AMPAR capture and endocytosis, but not to defects in AMPAR recycling or exocytosis (Fig. $8 F$ ).

\section{Discussion}

Multiple studies implicate Parkin as a regulator of glutamatergic neurotransmission (Fallon et al., 2002; Goldberg et al., 2003; Joch et al., 2007; Helton et al., 2008; Hanson et al., 2010; Maraschi et al., 2014), but its mechanism of action at synapses has remained unclear. For example, Parkin loss of function has been reported to enhance glutamatergic transmission (Helton et al., 2008) and also to attenuate it (Itier et al., 2003; Hanson et al., 2010), and the observed defects in transmission have been attributed to decreased presynaptic neurotransmitter release (Itier et al., 2003; Hanson et al., 2010) as well as to reduced postsynaptic efficacy (Goldberg et al., 2003). Our study, the first to specifically examine Parkin's role in the postsynaptic compartment of glutamatergic neurons, demonstrates its essential function in stabilizing Homer1 at the PSD, thereby maintaining endocytic zones for efficient AMPAR capture and internalization (Fig. $8 F$ ). In the absence of Parkin, Homerl levels are reduced and EZs are less efficiently coupled to the PSD, leading to AMPAR diffusion away from the synaptic cleft (Fig. 8F). Parkin loss of function therefore impairs excitatory synaptic transmission by reducing the number of cell-surface AMPARs available to detect presynaptic glutamate release.

\section{Parkin as an organizer of postsynaptic endocytic zones}

Disruption of EZs was previously linked to reduced cell-surface AMPAR levels and attenuated transmission, as synaptic AMPARs could no longer be efficiently captured, endocytosed, and reinserted at the cell surface, but instead diffused away (Lu et al., 2007; Petrini et al., 2009). We found that Parkin-deficient neurons exhibited multiple phenotypes indicative of EZ disruption, including reduced mEPSCs, eEPSCs, and cell-surface AMPARs, as well as decreased postsynaptic Homer1 levels, decreased density and PSD colocalization of the EZ protein and Homer1-binding partner Dynamin-3, and impaired GluAl internalization. However, two of the phenotypes we observed in Parkin-deficient hippocampal neurons differed from those previously reported after EZ disruption (Lu et al., 2007). For instance, we found that Parkin loss of function caused defects in GluA1 internalization after both 15 and 30 min incubation times, whereas EZ disruption via overexpression of the Dynamin-3 proline-rich domain (Dyn3PRD) was shown to impair GluAl internalization after 5 or 20 min but not $30 \mathrm{~min}$ of incubation. One potential explanation for this discrepancy is that Parkin loss of function more effectively disrupts EZ function than overexpression of Dyn3-PRD. Fur-

\section{$\leftarrow$}

(Figure legend continued.) puncta per field, unpaired $t$ test). $\boldsymbol{H}$, Immunoblot of primary hippocampal neurons cultured from E18 WT and Parkin KO rats, collected on 14 DIV, and probed with Parkin and tubulin antibodies. Note the absence of Parkin from the KO lysate. I, Immunoblot of lysates from HEK293T cells expressing Myc-Parkin and HA-Dynamin3, immunoprecipitated (IP) with IgG (control) or Myc antibody, and probed with HA or Myc antibodies. The arrowhead indicates Myc-Parkin (just below the lgG band). thermore, Parkin interacts with other endocytic proteins known to regulate AMPAR internalization, including endophilin-A, Eps15, and PICK1 (Chowdhury et al., 2006; Fallon et al., 2006; Hanley, 2006; Rial Verde et al., 2006; Joch et al., 2007; Trempe et al., 2009; Lin and Man, 2014), and the loss of these interactions in Parkin-deficient neurons may cause more profound endocytic defects than disruption of Homer1/Dynamin-3 binding alone.

The other difference noted between our studies and those performed previously was the effect on AMPAR recycling back to the cell surface. In particular, we found that Parkin deficiency did not alter the recycling of GluA1, whereas Dyn3-PRD-mediated disruption of EZs was reported to significantly impair synaptic GluA1/GluA2 recycling (Lu et al., 2007). One possible cause of this discrepancy is methodological, as we looked at endogenous GluA1 and normalized the intensity of recycled AMPARs to that of the internalized pool (thus taking into account the internalization defect at Parkin-deficient synapses), whereas Lu et al. (2007) examined transfected, HA-tagged GluA1 and HA-GluA2 and normalized the intensity of recycled receptors in a different way. Moreover, Lu et al. (2007) found that there was no recycling defect in the extrasynaptic pool of AMPARs, and we were unable to distinguish between synaptic and extrasynaptic GluA1 pools in our antibody feeding assays. Thus, it is conceivable that defects in synaptic AMPAR recycling were masked by normal extrasynaptic recycling in Parkin-deficient neurons and simply not detected. Whatever the differences, both of our studies demonstrate that reduced coupling of EZs to the PSD, whether through disruption of Parkin/Homer1 or Homer1/Dyn3 binding, ultimately results in the net loss of AMPARs from the neuronal cell surface.

\section{Parkin regulation of PSD composition}

We propose that Parkin-mediated stabilization of Homerl at the PSD is essential for proper EZ/PSD coupling and the efficient local capture, internalization, and replenishment of cell-surface AMPARs (Fig. 8F). This concept is consistent with our coimmunoprecipitation experiments showing direct binding between Parkin and Homer1, and with our finding that Homerl overexpression is sufficient to rescue the decrease in cell-surface GluA1 levels observed in Parkin-deficient neurons. Parkin may also influence PSD composition through other mechanisms. For instance, previous studies have shown that Parkin interacts with the PDZ domain-containing proteins CASK and PICK1 (Fallon et al., 2002; Joch et al., 2007), which in turn interact with the PSD proteins PSD-95, SAP-97, and GluA2 (Nix et al., 2000; Hirbec et al., 2002; Leonoudakis et al., 2004). Although we did not detect changes in PSD-95 or GluA2/3 levels in purified PSDs from Parkin KO brain tissue, our survey of PSD proteins was not extensive. It is possible that the levels and/or localization of other Parkin or Homer1-interacting proteins (i.e., NMDA receptors, mGluR5, Shank; Shiraishi-Yamaguchi and Furuichi, 2007; Gao et al., 2013; Marton et al., 2015) are also affected. Future studies will address this important question.

We also cannot rule out a role for Parkin's ubiquitin ligase activity in regulating PSD protein levels or stability. Interestingly, a recent study showed that the kainate receptor subunit GluK2 is a Parkin substrate whose degradation is regulated by Parkinmediated ubiquitination (Maraschi et al., 2014). Parkin was also recently reported to ubiquitinate Dynamin-1 (Cao et al., 2014), raising the possibility that it could directly regulate Dynamin-3 stability rather than working indirectly through Homer1. However, whereas the levels of Parkin substrates, including GluK2, are reported to increase after Parkin loss of function (Maraschi et al., 2014), we find that the levels of GluA1, Homer1, and CASK all 
A

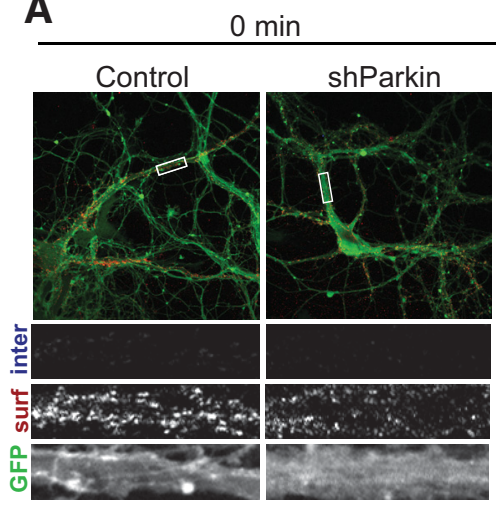

B

$15 \mathrm{~min}$ internalized/surface GluA1

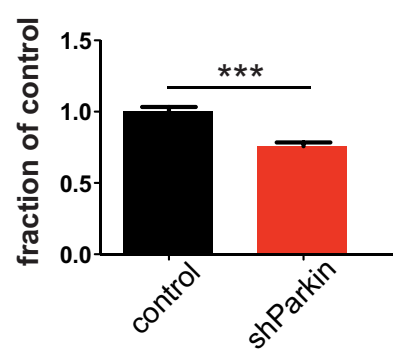

D

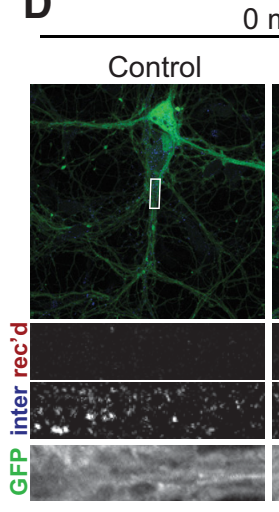

$0 \min$
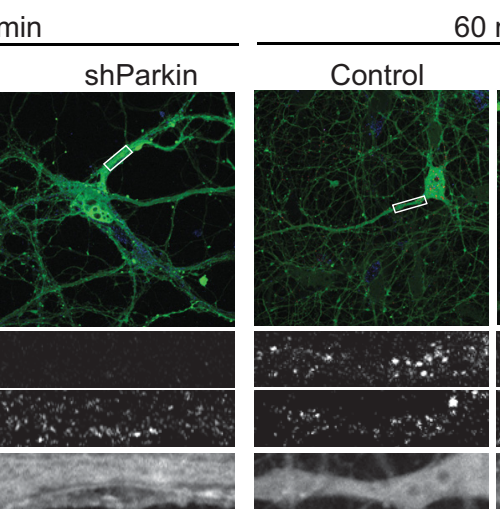

$60 \mathrm{~min}$

$\mathbf{F}$

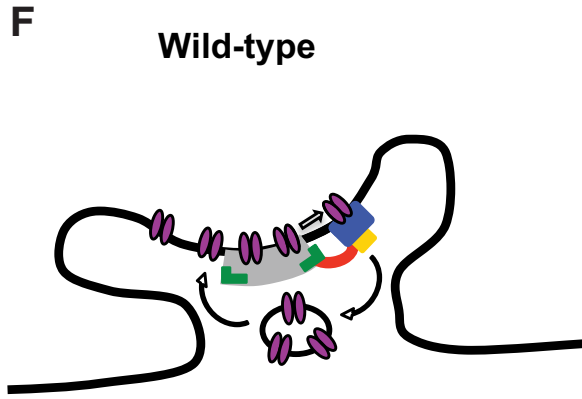

$15 \min$
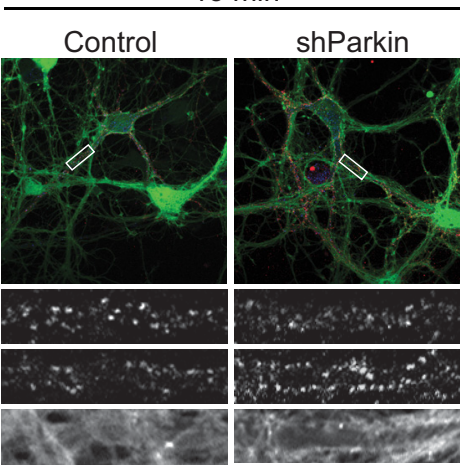

C

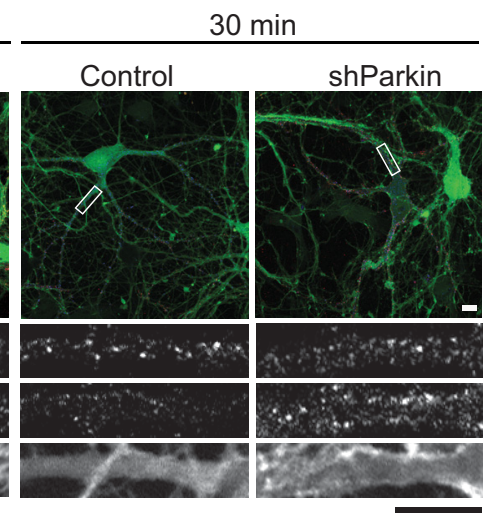

$30 \mathrm{~min}$ internalized/surface GluA1

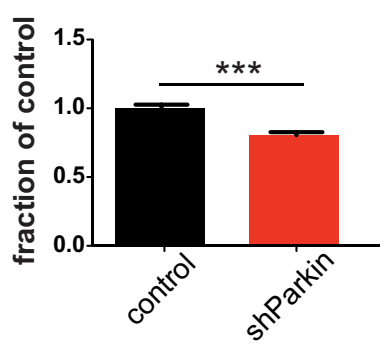

E
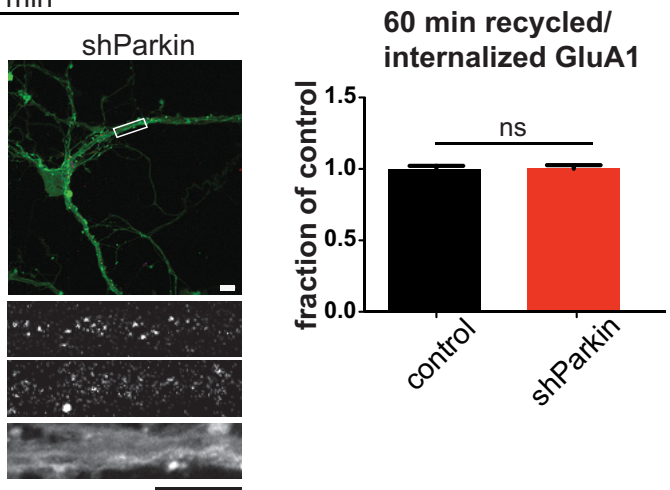

\section{Parkin deficient}

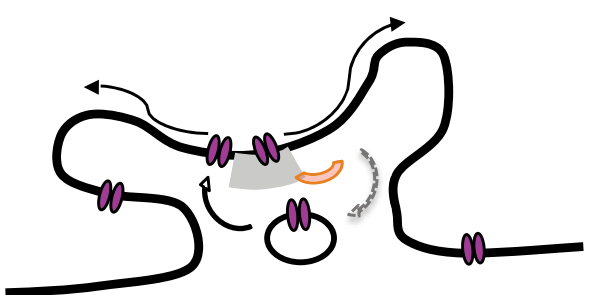

Figure 8. Impaired AMPAR internalization but not recycling in Parkin-deficient neurons. $A$, Images of 15 DIV hippocampal neurons expressing soluble GFP $+/-$ shParkin, immunostained for cell-surface (surf) and internalized (inter) GluA1 after 0,15 , or 30 min incubation at $37^{\circ} \mathrm{C}$. Scale bars, $10 \mu \mathrm{m}$. B, Quantification of GluA1 internalization at 15 min, expressed as the ratio of internalized to cell-surface GluA1 and normalized to GFP control condition ( $n \geq 10$ fields of view per condition, $>50$ GluA1 puncta per field, results confirmed in 3 independent experiments; ${ }^{* * *} p<0.0001$, unpaired $t$ test). C, Quantification of GluA1 internalization at $30 \mathrm{~min}$, expressed as the ratio of internalized to cell-surface GluA1 and normalized to the GFP control condition ( $n \geq 10$ fields of view per condition, $>50$ GluA1 puncta per field, results confirmed in 3 independent experiments; ${ }^{* * *} p<0.0001$, unpaired $t$ test). D, Images of 15 DIV hippocampal neurons expressing soluble GFP $+/-$ shParkin and immunostained for internalized (inter) or recycled (rec'd) GluA1 after 0 or 60 min incubation at $37^{\circ}$. Scale bars, $10 \mu \mathrm{m}$. E, Quantification of GluA1 recycling at 60 min, expressed as the ratio of recycled to internalized GluA1 and normalized to the GFP control condition ( $n \geq 10$ fields of view per condition, $>50$ GluA1 puncta per field, results confirmed in 3 independent experiments; $p<0.0001$, unpaired $t$ test). $F$, Model of how Parkin deficiency may disrupt postsynaptic AMPAR recycling. In wild-type neurons, Parkin stabilizes Homer1 at the PSD, allowing for PSD/EZ coupling via Homer1/Dynamin-3 interactions and thereby supporting efficient AMPAR capture, internalization, and reinsertion at the cell surface (Lu et al., 2007; Petrini et al., 2009). Parkin-deficient synapses have decreased Homer1 levels, leading to reduced PSD/EZ coupling, impaired AMPAR capture and internalization, and ultimately the diffusion of cell-surface AMPARs away from synapses. 
decrease, suggesting that any Parkin-mediated ubiquitination acts indirectly, or by mediating protein trafficking rather than degradation.

\section{Parkin and presynaptic function}

Our findings demonstrate a critical role for Parkin in postsynaptic AMPAR-mediated signaling. They also hint at a role for Parkin in presynaptic neurotransmitter release, as we observed significantly decreased mEPSC frequency in hippocampal neurons isolated from Parkin $\mathrm{KO}$ rats (Fig. $1 G$ ), a phenotype not observed in our mixed culture preparation wherein a majority of presynaptic inputs derived from wild-type, untransduced neurons. Several electrophysiology studies (Itier et al., 2003; Hanson et al., 2010) and reports that Parkin ubiquitinates the synaptic vesicle-associated proteins CDCrel-1 and synaptotagmin XI (Zhang et al., 2000; Huynh et al., 2003), as well as the presynaptic endocytic machinery, including endophilin-A, dynamin-1, and synaptojanin (Trempe et al., 2009; Cao et al., 2014), further support a role for Parkin in the presynaptic compartment. Intriguingly, Parkin levels are significantly and specifically increased in the brains of endophilin knock-out mice (Cao et al., 2014), suggesting a reciprocal relationship between these two proteins. Moreover, endophilin interacts genetically and biochemically with LRRK2, a kinase that regulates synaptic vesicle cycling and whose mutation is a major genetic cause of PD (Matta et al., 2012; Arranz et al., 2015; Konno et al., 2016). Clearly, additional studies are needed to investigate Parkin's functions and links to other $\mathrm{PD}$-associated proteins in the presynaptic compartment.

\section{Parkin deficiency in neurological disease}

There are few effective treatments for the nonmotor symptoms of Parkinson's disease, which include cognitive dysfunction, memory impairment, and dementia (Svenningsson et al., 2012; Calabresi et al., 2013; Cosgrove et al., 2015). Although these symptoms are thought to arise from defects in excitatory glutamatergic transmission, very little is known about their underlying cellular and molecular mechanisms. Moreover, Parkin deficiency is implicated in other brain disorders characterized by dysfunction of glutamatergic signaling, including Alzheimer's disease and autism (Scheuerle and Wilson, 2011; Roberts et al., 2014; Sun et al., 2014; Olah et al., 2015). Not only do our findings provide new insights into the role of Parkin at glutamatergic synapses, they also suggest potential therapeutic strategies for treating PD and other disorders resulting from Parkin deficiency. For instance, Homer1 regulates synaptic plasticity via modulation of mGluR5 and NMDA receptors (Gao et al., 2013; Marton et al., 2015), both of which are highly druggable targets (Matosin et al., 2015; Park et al., 2015; Scharf et al., 2015; Tsai, 2016). It is therefore conceivable that the cognitive deficits present in patients with Parkin mutation/loss of function could be ameliorated by pharmacologically altering these Homer1-mediated signaling pathways.

In summary, we report that Parkin has an essential role in the postsynaptic compartment of glutamatergic hippocampal neurons, where it stabilizes Homer1 and thereby regulates EZ density, synaptic cell-surface AMPAR levels, and ultimately the ability of neurons to respond to presynaptic glutamate release. These findings suggest a potential mechanism through which Parkin deficiency contributes to the dysfunction of glutamatergic signaling in Parkinson's disease and other brain disorders.

\section{References}

Albuquerque C, Joseph DJ, Choudhury P, MacDermott AB (2009) Dissection, plating, and maintenance of cortical astrocyte cultures. Cold Spring Harb Protoc 2009:pdb.prot5273. CrossRef Medline
Arons MH, Thynne CJ, Grabrucker AM, Li D, Schoen M, Cheyne JE, Boeckers TM, Montgomery JM, Garner CC (2012) Autismassociated mutations in ProSAP2/Shank3 impair synaptic transmission and neurexin-neuroligin-mediated transsynaptic signaling. J Neurosci 32:14966-14978. CrossRef Medline

Arranz AM, Delbroek L, Van Kolen K, Guimaraes MR, Mandemakers W, Daneels G, Matta S, Calafate S, Shaban H, Baatsen P, De Bock PJ, Gevaert K, Vanden Berghe P, Verstreken P, De Strooper B, Moechars D (2015) LRRK2 functions in synaptic vesicle endocytosis through a kinasedependent mechanism. J Cell Sci 128:541-552. CrossRef Medline

Banker G, Goslin K (1998) Culturing nerve cells, Ed 2. Cambridge, MA: MIT.

Bartsch T, Wulff P (2015) The hippocampus in aging and disease: from plasticity to vulnerability. Neuroscience 309:1-16. CrossRef Medline

Berger AK, Cortese GP, Amodeo KD, Weihofen A, Letai A, LaVoie MJ (2009) Parkin selectively alters the intrinsic threshold for mitochondrial cytochrome c release. Hum Mol Genet 18:4317-4328. CrossRef Medline

Bermejo MK, Milenkovic M, Salahpour A, Ramsey AJ (2014) Preparation of synaptic plasma membrane and postsynaptic density proteins using a discontinuous sucrose gradient. J Vis Exp e51896. CrossRef Medline

Calabresi P, Castrioto A, Di Filippo M, Picconi B (2013) New experimental and clinical links between the hippocampus and the dopaminergic system in Parkinson's disease. Lancet Neurol 12:811-821. CrossRef Medline

Cao M, Milosevic I, Giovedi S, De Camilli P (2014) Upregulation of Parkin in endophilin mutant mice. J Neurosci 34:16544-16549. CrossRef Medline

Caulfield TR, Fiesel FC, Springer W (2015) Activation of the E3 ubiquitin ligase Parkin. Biochem Soc Trans 43:269-274. CrossRef Medline

Chowdhury S, Shepherd JD, Okuno H, Lyford G, Petralia RS, Plath N, Kuhl D, Huganir RL, Worley PF (2006) Arc/Arg3.1 interacts with the endocytic machinery to regulate AMPA receptor trafficking. Neuron 52:445459. CrossRef Medline

Cosgrove J, Alty JE, Jamieson S (2015) Cognitive impairment in Parkinson's disease. Postgrad Med J 91:212-220. CrossRef

Delgado-Martinez I, Nehring RB, Sorensen JB (2007) Differential abilities of SNAP-25 homologs to support neuronal function. J Neurosci 27:93809391. CrossRef Medline

Fallon L, Moreau F, Croft BG, Labib N, Gu WJ, Fon EA (2002) Parkin and CASK/LIN-2 associate via a PDZ-mediated interaction and are colocalized in lipid rafts and postsynaptic densities in brain. J Biol Chem 277:486-491. CrossRef Medline

Fallon L, Belanger CM, Corera AT, Kontogiannea M, Regan-Klapisz E, Moreau F, Voortman J, Haber M, Rouleau G, Thorarinsdottir T, Brice A, van Bergen En Henegouwen PM, Fon EA (2006) A regulated interaction with the UIM protein Eps15 implicates parkin in EGF receptor trafficking and PI(3)K-Akt signalling. Nat Cell Biol 8:834-842. CrossRef Medline

Feany MB, Pallanck LJ (2003) Parkin: a multipurpose neuroprotective agent? Neuron 38:13-16. CrossRef Medline

Gao C, Tronson NC, Radulovic J (2013) Modulation of behavior by scaffolding proteins of the post-synaptic density. Neurobiol Learn Mem 105: 3-12. CrossRef Medline

Goldberg MS, Fleming SM, Palacino JJ, Cepeda C, Lam HA, Bhatnagar A, Meloni EG, Wu N, Ackerson LC, Klapstein GJ, Gajendiran M, Roth BL, Chesselet MF, Maidment NT, Levine MS, Shen J (2003) Parkindeficient mice exhibit nigrostriatal deficits but not loss of dopaminergic neurons. J Biol Chem 278:43628-43635. CrossRef Medline

Greene JC, Whitworth AJ, Kuo I, Andrews LA, Feany MB, Pallanck LJ (2003) Mitochondrial pathology and apoptotic muscle degeneration in Drosophila parkin mutants. Proc Natl Acad Sci US A 100:4078-4083. CrossRef Medline

Hanley JG (2006) Molecular mechanisms for regulation of AMPAR trafficking by PICK1. Biochem Soc Trans 34:931-935. CrossRef Medline

Hanson JE, Orr AL, Madison DV (2010) Altered hippocampal synaptic physiology in aged parkin-deficient mice. Neuromolecular Med 12:270276. CrossRef Medline

Helton TD, Otsuka T, Lee MC, Mu Y, Ehlers MD (2008) Pruning and loss of excitatory synapses by the parkin ubiquitin ligase. Proc Natl Acad Sci U S A 105:19492-19497. CrossRef Medline

Hirbec H, Perestenko O, Nishimune A, Meyer G, Nakanishi S, Henley JM, Dev KK (2002) The PDZ proteins PICK1, GRIP, and syntenin bind multiple glutamate receptor subtypes. Analysis of PDZ binding motifs. J Biol Chem 277:15221-15224. CrossRef Medline 
Huynh DP, Scoles DR, Nguyen D, Pulst SM (2003) The autosomal recessive juvenile Parkinson disease gene product, parkin, interacts with and ubiquitinates synaptotagmin XI. Hum Mol Genet 12:2587-2597. CrossRef Medline

Itier JM, Ibanez P, Mena MA, Abbas N, Cohen-Salmon C, Bohme GA, Laville M, Pratt J, Corti O, Pradier L, Ret G, Joubert C, Periquet M, Araujo F, Negroni J, Casarejos MJ, Canals S, Solano R, Serrano A, Gallego E, et al. (2003) Parkin gene inactivation alters behaviour and dopamine neurotransmission in the mouse. Hum Mol Genet 12:2277-2291. CrossRef Medline

Joch M, Ase AR, Chen CX, MacDonald PA, Kontogiannea M, Corera AT, Brice A, Seguela P, Fon EA (2007) Parkin-mediated monoubiquitination of the PDZ protein PICK1 regulates the activity of acid-sensing ion channels. Mol Biol Cell 18:3105-3118. CrossRef Medline

Kitada T, Pisani A, Karouani M, Haburcak M, Martella G, Tscherter A, Platania P, Wu B, Pothos EN, Shen J (2009) Impaired dopamine release and synaptic plasticity in the striatum of parkin-/- mice. J Neurochem 110: 613-621. CrossRef Medline

Konno T, Siuda J, Wszolek ZK (2016) Genetics of Parkinson's disease: a review of SNCA and LRRK2. Wiadomosci lekarskie 69:328-332.

Leal-Ortiz S, Waites CL, Terry-Lorenzo R, Zamorano P, Gundelfinger ED, Garner CC (2008) Piccolo modulation of Synapsin1a dynamics regulates synaptic vesicle exocytosis. J Cell Biol 181:831-846. CrossRef Medline

Leonoudakis D, Conti LR, Radeke CM, McGuire LM, Vandenberg CA (2004) A multiprotein trafficking complex composed of SAP97, CASK, Veli, and Mint1 is associated with inward rectifier Kir2 potassium channels. J Biol Chem 279:19051-19063. CrossRef Medline

Leroy E, Anastasopoulos D, Konitsiotis S, Lavedan C, Polymeropoulos MH (1998) Deletions in the Parkin gene and genetic heterogeneity in a Greek family with early onset Parkinson's disease. Hum Genet 103:424-427. CrossRef Medline

Lin A, Man HY (2014) Endocytic adaptor epidermal growth factor receptor substrate 15 (Eps15) is involved in the trafficking of ubiquitinated $\alpha$-amino-3-hydroxy-5-methyl-4-isoxazolepropionic acid receptors. J Biol Chem 289:24652-24664. CrossRef Medline

Lu J, Helton TD, Blanpied TA, Racz B, Newpher TM, Weinberg RJ, Ehlers MD (2007) Postsynaptic positioning of endocytic zones and AMPA receptor cycling by physical coupling of dynamin-3 to Homer. Neuron 55:874-889. CrossRef Medline

Lucking CB, Abbas N, Durr A, Bonifati V, Bonnet AM, de Broucker T, De Michele G, Wood NW, Agid Y, Brice A (1998) Homozygous deletions in parkin gene in European and North African families with autosomal recessive juvenile parkinsonism. The European Consortium on Genetic Susceptibility in Parkinson's Disease and the French Parkinson's Disease Genetics Study Group. Lancet 352:1355-1356. CrossRef Medline

Maraschi A, Ciammola A, Folci A, Sassone F, Ronzitti G, Cappelletti G, Silani V, Sato S, Hattori N, Mazzanti M, Chieregatti E, Mulle C, Passafaro M, Sassone J (2014) Parkin regulates kainate receptors by interacting with the GluK2 subunit. Nat Commun 5:5182. CrossRef Medline

Marton TM, Hussain Shuler MG, Worley PF (2015) Homer 1a and mGluR5 phosphorylation in reward-sensitive metaplasticity: a hypothesis of neuronal selection and bidirectional synaptic plasticity. Brain Res 1628:1728. CrossRef Medline

Matosin N, Fernandez-Enright F, Lum JS, Newell KA (2015) Shifting towards a model of mGluR5 dysregulation in schizophrenia: consequences for future schizophrenia treatment. Neuropharmacology pii:S00283908(15)30049-6. CrossRef Medline

Matta S, Van Kolen K, da Cunha R, van den Bogaart G, Mandemakers W, Miskiewicz K, De Bock PJ, Morais VA, Vilain S, Haddad D, Delbroek L, Swerts J, Chávez-Gutiérrez L, Esposito G, Daneels G, Karran E, Holt M, Gevaert K, Moechars DW, De Strooper B, et al. (2012) LRRK2 controls an EndoA phosphorylation cycle in synaptic endocytosis. Neuron 75: 1008-1021. CrossRef Medline

Nix SL, Chishti AH, Anderson JM, Walther Z (2000) hCASK and hDlg associate in epithelia, and their src homology 3 and guanylate kinase domains participate in both intramolecular and intermolecular interactions. J Biol Chem 275:41192-41200. CrossRef Medline

Olah Z, Kalman J, Toth ME, Zvara A, Santha M, Ivitz E, Janka Z, Pakaski M
(2015) Proteomic analysis of cerebrospinal fluid in Alzheimer's disease: wanted dead or alive. J Alzheimers Dis 44:1303-1312. CrossRef Medline

Park M, Niciu MJ, Zarate CA Jr (2015) Novel glutamatergic treatments for severe mood disorders. Curr Behav Neurosci Rep 2:198-208. CrossRef Medline

Penzes P, Buonanno A, Passafaro M, Sala C, Sweet RA (2013) Developmental vulnerability of synapses and circuits associated with neuropsychiatric disorders. J Neurochem 126:165-182. CrossRef Medline

Petrini EM, Lu J, Cognet L, Lounis B, Ehlers MD, Choquet D (2009) Endocytic trafficking and recycling maintain a pool of mobile surface AMPA receptors required for synaptic potentiation. Neuron 63:92-105. CrossRef Medline

Piguel NH, Fievre S, Blanc JM, Carta M, Moreau MM, Moutin E, Pinheiro VL, Medina C, Ezan J, Lasvaux L, et al. (2014) Scribble1/AP2 complex coordinates NMDA receptor endocytic recycling. Cell Rep 9:712-727. CrossRef Medline

Raskin J, Cummings J, Hardy J, Schuh K, Dean RA (2015) Neurobiology of Alzheimer's disease: integrated molecular, physiological, anatomical, biomarker, and cognitive dimensions. Curr Alzheimer Res 12:712-722. CrossRef Medline

Rial D, Castro AA, Machado N, Garcao P, Goncalves FQ, Silva HB, Tome AR, Kofalvi A, Corti O, Raisman-Vozari R, Cunha RA, Prediger RD (2014) Behavioral phenotyping of Parkin-deficient mice: looking for early preclinical features of Parkinson's disease. PLoS One 9:e114216. CrossRef Medline

Rial Verde EM, Lee-Osbourne J, Worley PF, Malinow R, Cline HT (2006) Increased expression of the immediate-early gene arc/arg3.1 reduces AMPA receptor-mediated synaptic transmission. Neuron 52:461-474. CrossRef Medline

Roberts JL, Hovanes K, Dasouki M, Manzardo AM, Butler MG (2014) Chromosomal microarray analysis of consecutive individuals with autism spectrum disorders or learning disability presenting for genetic services. Gene 535:70-78. CrossRef Medline

Scharf SH, Jaeschke G, Wettstein JG, Lindemann L (2015) Metabotropic glutamate receptor 5 as drug target for Fragile X syndrome. Curr Opin Pharmacol 20:124-134. CrossRef Medline

Scheuerle A, Wilson K (2011) PARK2 copy number aberrations in two children presenting with autism spectrum disorder: further support of an association and possible evidence for a new microdeletion/microduplication syndrome. Am J Med Genet B Neuropsychiatr Genet 156B:413-420. CrossRef Medline

Scuderi S, La Cognata V, Drago F, Cavallaro S, D'Agata V (2014) Alternative splicing generates different parkin protein isoforms: evidences in human, rat, and mouse brain. Biomed Res Int 2014:690796. CrossRef Medline

Shiraishi-Yamaguchi Y, Furuichi T (2007) The Homer family proteins. Genome Biol 8:206. CrossRef Medline

Sun J, Song F, Wang J, Han G, Bai Z, Xie B, Feng X, Jia J, Duan Y, Lei H (2014) Hidden risk genes with high-order intragenic epistasis in Alzheimer's disease. J Alzheimers Dis 41:1039-1056. CrossRef Medline

Svenningsson P, Westman E, Ballard C, Aarsland D (2012) Cognitive impairment in patients with Parkinson's disease: diagnosis, biomarkers, and treatment. Lancet Neurol 11:697-707. CrossRef Medline

Trempe JF, Chen CX, Grenier K, Camacho EM, Kozlov G, McPherson PS, Gehring K, Fon EA (2009) SH3 domains from a subset of BAR proteins define a Ubl-binding domain and implicate parkin in synaptic ubiquitination. Mol Cell 36:1034-1047. CrossRef Medline

Tsai GE (2016) Ultimate translation: developing therapeutics targeting on N-methyl-d-aspartate receptor. Adv Pharmacol 76:257-309. CrossRef Medline

Waites CL, Specht CG, Hartel K, Leal-Ortiz S, Genoux D, Li D, Drisdel RC, Jeyifous O, Cheyne JE, Green WN, Montgomery JM, Garner CC (2009) Synaptic SAP97 isoforms regulate AMPA receptor dynamics and access to presynaptic glutamate. J Neurosci 29:4332-4345. CrossRef Medline

Wang X, Winter D, Ashrafi G, Schlehe J, Wong YL, Selkoe D, Rice S, Steen J, LaVoie MJ, Schwarz TL (2011) PINK1 and Parkin target Miro for phosphorylation and degradation to arrest mitochondrial motility. Cell 147: 893-906. CrossRef Medline

Zhang Y, Gao J, Chung KK, Huang H, Dawson VL, Dawson TM (2000) Parkin functions as an E2-dependent ubiquitin- protein ligase and promotes the degradation of the synaptic vesicle-associated protein, CDCrel-1. Proc Natl Acad Sci U S A 97:13354-13359. CrossRef Medline 